
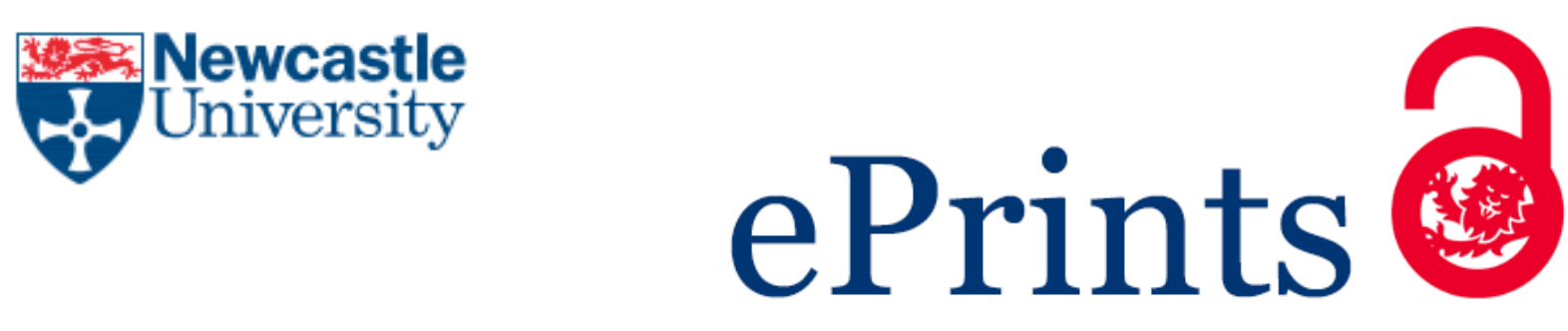

Zaleski DP, Mullaney JC, Bittner DM, Tew DP, Walker NR, Legon AC. Interaction of a pseudo- $\pi \mathrm{C}-\mathrm{C}$ bond with cuprous and argentous chlorides: Cyclopropane... CuCl and cyclopropane...AgCl investigated by rotational spectroscopy and $a b$ initio calculations. Journal of Chemical Physics 2015, 143: 164314.

\title{
Copyright:
}

Copyright 2015 American Institute of Physics. This article may be downloaded for personal use only. Any other use requires prior permission of the author and the American Institute of Physics.

The following article appeared in J. Chem. Phys. 143, 164314 (2015) and may be found at:

http://dx.doi.org/10.1063/1.4934539

Date deposited:

$30 / 10 / 2015$ 


\section{A|P|l $\begin{aligned} & \text { The Journal of } \\ & \text { Chemical Physics }\end{aligned}$}

\section{Interaction of a pseudo-m $\mathbf{C}-\mathbf{C}$ bond with cuprous and argentous chlorides: \\ Cyclopropane $\cdots \mathrm{CuCl}$ and cyclopropane $\cdots A \mathrm{AgCl}$ investigated by rotational spectroscopy and ab initio calculations}

Daniel P. Zaleski, John C. Mullaney, Dror M. Bittner, David P. Tew, Nicholas R. Walker, and Anthony C. Legon

Citation: The Journal of Chemical Physics 143, 164314 (2015); doi: 10.1063/1.4934539

View online: http://dx.doi.org/10.1063/1.4934539

View Table of Contents: http://scitation.aip.org/content/aip/journal/jcp/143/16?ver=pdfcov

Published by the AIP Publishing

\section{Articles you may be interested in}

Distortion of ethyne on coordination to silver acetylide, $\mathrm{C} 2 \mathrm{H} 2 \ldots \mathrm{AgCCH}$, characterised by broadband rotational spectroscopy and ab initio calculations

J. Chem. Phys. 140, 124310 (2014); 10.1063/1.4868035

Distortion of ethyne on formation of a $\pi$ complex with silver chloride: $\mathrm{C} 2 \mathrm{H} 2 \cdots \mathrm{Ag}-\mathrm{Cl}$ characterised by rotational spectroscopy and ab initio calculations

J. Chem. Phys. 137, 174302 (2012); 10.1063/1.4761895

Molecular geometry of OC...Agl determined by broadband rotational spectroscopy and ab initio calculations J. Chem. Phys. 136, 064306 (2012); 10.1063/1.3683221

A prototype transition-metal olefin complex $\mathrm{C} 2 \mathrm{H} 4 \cdots \mathrm{AgCl}$ synthesised by laser ablation and characterised by rotational spectroscopy and ab initio methods

J. Chem. Phys. 135, 024315 (2011); 10.1063/1.3604821

Monohydrates of cuprous chloride and argentous chloride: $\mathrm{H} 2 \mathrm{O} \ldots \mathrm{CuCl}$ and $\mathrm{H} 2 \mathrm{O} \ldots \mathrm{AgCl}$ characterized by rotational spectroscopy and ab initio calculations

J. Chem. Phys. 134, 134305 (2011); 10.1063/1.3561305

\section{AIP $\left.\right|_{\text {APL Photonics }}$}

APL Photonics is pleased to announce Benjamin Eggleton as its Editor-in-Chief

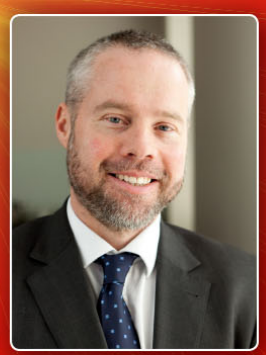




\title{
Interaction of a pseudo- $\pi \mathbf{C}-\mathbf{C}$ bond with cuprous and argentous chlorides: Cyclopropane...CuCl and cyclopropane...AgCl investigated by rotational spectroscopy and ab initio calculations
}

\author{
Daniel P. Zaleski, ${ }^{1}$ John C. Mullaney, ${ }^{1}$ Dror M. Bittner, ${ }^{1}$ David P. Tew, ${ }^{2}$ \\ Nicholas R. Walker, ${ }^{1, a)}$ and Anthony C. Legon ${ }^{2, a)}$ \\ ${ }^{1}$ School of Chemistry, Newcastle University, Bedson Building, \\ Newcastle-Upon-Tyne NE1 7RU, United Kingdom \\ ${ }^{2}$ School of Chemistry, University of Bristol, Bristol BS8 1TS, United Kingdom
}

(Received 30 August 2015; accepted 12 October 2015; published online 30 October 2015)

\begin{abstract}
Strongly bound complexes $\left(\mathrm{CH}_{2}\right)_{3} \cdots \mathrm{MCl}(\mathrm{M}=\mathrm{Cu}$ or $\mathrm{Ag})$, formed by non-covalent interaction of cyclopropane and either cuprous chloride or argentous chloride, have been generated in the gas phase by means of the laser ablation of either copper or silver metal in the presence of supersonically expanded pulses of a gas mixture containing small amounts of cyclopropane and carbon tetrachloride in a large excess of argon. The rotational spectra of the complexes so formed were detected with a chirped-pulse, Fourier transform microwave spectrometer and analysed to give rotational constants and $\mathrm{Cu}$ and $\mathrm{Cl}$ nuclear quadrupole coupling constants for eight isotopologues of each of $\left(\mathrm{CH}_{2}\right)_{3} \cdots \mathrm{CuCl}$ and $\left(\mathrm{CH}_{2}\right)_{3} \cdots \mathrm{AgCl}$. The geometry of each of these complexes was established unambiguously to have $\mathrm{C}_{2 \mathrm{v}}$ symmetry, with the three $\mathrm{C}$ atoms coplanar, and with the $\mathrm{MCl}$ molecule lying along a median of the cyclopropane $\mathrm{C}_{3}$ triangle. This median coincides with the principal inertia axis $a$ in each of the two complexes $\left(\mathrm{CH}_{2}\right)_{3} \cdots \mathrm{MCl}$. The $\mathrm{M}$ atom interacts with the pseudo- $\pi$ bond linking the pair of equivalent carbon atoms ${ }^{\mathrm{F}} \mathrm{C}(\mathrm{F}=$ front $)$ nearest to it, so that $\mathrm{M}$ forms a non-covalent bond to one $\mathrm{C}-\mathrm{C}$ edge of the cyclopropane molecule. The $\left(\mathrm{CH}_{2}\right)_{3} \cdots \mathrm{MCl}$ complexes have similar angular geometries to those of the hydrogen- and halogen-bonded analogues $\left(\mathrm{CH}_{2}\right)_{3} \cdots \mathrm{HCl}$ and $\left(\mathrm{CH}_{2}\right)_{3} \cdots \mathrm{ClF}$, respectively. Quantitative details of the geometries were determined by interpretation of the observed rotational constants and gave results in good agreement with those from ab initio calculations carried out at the $\operatorname{CCSD}(\mathrm{T})(\mathrm{F} 12 *) /$ aug-cc-pVTZ-F12 level of theory. Interesting geometrical features are the lengthening of the ${ }^{\mathrm{F}} \mathrm{C}-{ }^{\mathrm{F}} \mathrm{C}$ bond and the shrinkage of the two equivalent ${ }^{\mathrm{B}} \mathrm{C}-{ }^{\mathrm{F}} \mathrm{C}(\mathrm{B}=$ back) bonds relative to the $\mathrm{C}-\mathrm{C}$ bond in cyclopropane itself. The expansions of the ${ }^{\mathrm{F}} \mathrm{C}-{ }^{\mathrm{F}} \mathrm{C}$ bond are $0.1024(9) \AA$ and $0.0727(17) \AA$ in $\left(\mathrm{CH}_{2}\right)_{3} \cdots \mathrm{CuCl}$ and $\left(\mathrm{CH}_{2}\right)_{3} \cdots \mathrm{AgCl}$, respectively, according to the determined $r_{0}$ geometries. The $\mathrm{C}-\mathrm{C}$ bond lengthening is in each case about four times that observed by similar methods in the corresponding complexes of $\mathrm{MCl}$ with ethyne and ethene, even though the cyclopropane complexes are more weakly bound than their ethyne and ethene analogues. Reasons for the larger increase in $r(\mathrm{CC})$ in the pseudo- $\pi$ complexes are discussed. (C) 2015 AIP Publishing LLC. [http://dx.doi.org/10.1063/1.4934539]
\end{abstract}

\section{INTRODUCTION}

We report here the rotational spectra of two complexes of the type $\left(\mathrm{CH}_{2}\right)_{3} \cdots \mathrm{MCl}$, formed by the non-covalent interaction of cyclopropane $\left(\mathrm{CH}_{2}\right)_{3}$ with either $\mathrm{CuCl}$ or $\mathrm{AgCl}$. These hitherto unknown molecules were created by the reaction of laser-ablated copper or silver in the presence of a suitably timed pulse of a supersonically expanded gas mixture composed of small amounts of cyclopropane and carbon tetrachloride $\mathrm{CCl}_{4}$ in a large excess of argon. The rotational spectra of the $\left(\mathrm{CH}_{2}\right)_{3} \cdots \mathrm{MCl}$ molecules so generated were recorded by means of a chirped-pulse, Fourier-transform microwave (CP-FTMW) spectrometer.

The formation of a bond between a transition metal atom and an alkene, or alkyne, can lead to extensive geometrical

\footnotetext{
a) Authors to whom correspondence should be addressed. Electronic addresses: a.c.legon@bristol.ac.uk and nick.walker@newcastle.ac.uk
}

rearrangement within the hydrocarbon. For example, Walters et al. ${ }^{1}$ performed a combined infrared spectroscopic and theoretical study of the structures of $\mathrm{Ni}^{+}\left(\mathrm{C}_{2} \mathrm{H}_{2}\right)_{n}$, where $n$ is an integer. They interpreted their observations to establish that the $\mathrm{C} \equiv \mathrm{C}$ bond of ethyne weakens on formation of $\mathrm{Ni}^{+}\left(\mathrm{C}_{2} \mathrm{H}_{2}\right)$, with a concomitant displacement of hydrogen atoms from the $\mathrm{C} \equiv \mathrm{C}$ axis in the direction away from the approach of $\mathrm{Ni}^{+}$. The Dewar-Chatt-Duncanson interpretation ${ }^{2}$ of the mechanism for this type of bond formation invokes donation of electron density from $\pi$ orbitals of the hydrocarbon into unfilled d-orbitals on the metal, with a reciprocal transfer of electrons from occupied d-orbitals of the metal into $\pi^{*}$ antibonding orbitals of the hydrocarbon. The reciprocal transfers cooperate to enhance the bond strength. We have initiated an extensive research program $^{3-15}$ aimed at exploring the nature of the non-covalent interaction between simple Lewis bases $\mathrm{B}$ such as $\mathrm{N}_{2}, \mathrm{NH}_{3}$, $\mathrm{H}_{2} \mathrm{O}, \mathrm{H}_{2} \mathrm{~S}, \mathrm{C}_{2} \mathrm{H}_{2}$, and $\mathrm{C}_{2} \mathrm{H}_{4}$ and the metal atom in the transition metal halides $\mathrm{CuX}$ or $\mathrm{AgX}$ in isolated complexes $\mathrm{B} \cdots \mathrm{MX}$ 

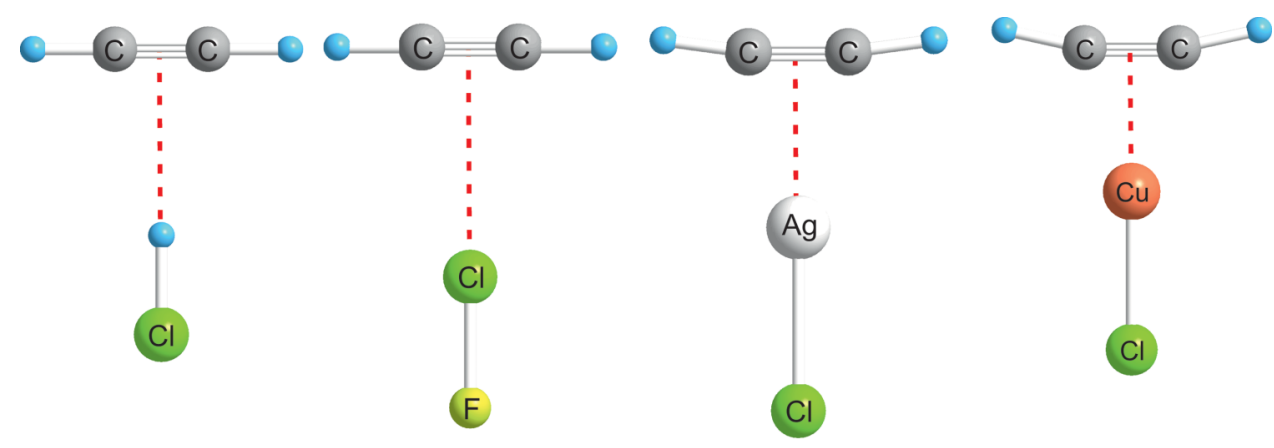

(a)
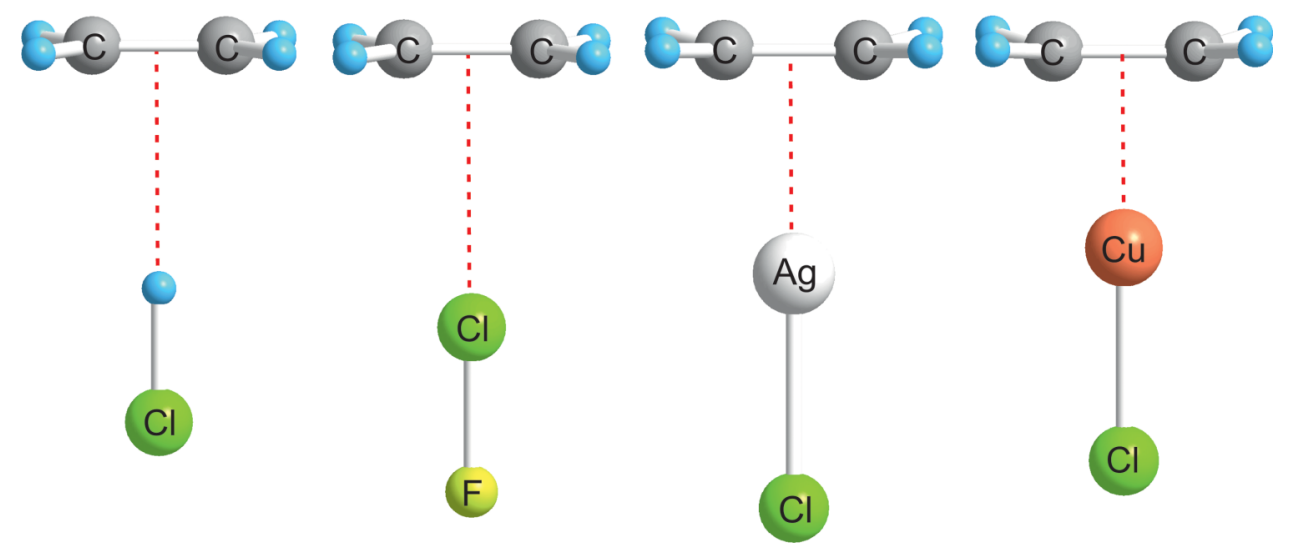

FIG. 1. (a) The geometries of complexes of ethyne with various Lewis acids, as determined from their rotational spectra. Drawings are to scale. In order of increasing non-covalent interaction strength, they are $\mathrm{C}_{2} \mathrm{H}_{2} \cdots \mathrm{HCl}, \mathrm{C}_{2} \mathrm{H}_{2} \cdots \mathrm{ClF}$, $\mathrm{C}_{2} \mathrm{H}_{2} \cdots \mathrm{AgCl}$, and $\mathrm{C}_{2} \mathrm{H}_{2} \cdots \mathrm{CuCl}$. In each, the Lewis acid lies along a $\mathrm{C}_{2}$ axis of ethyne. Note the distortion of ethyne in the $\mathrm{AgCl}$ and $\mathrm{CuCl}$ complexes. (b) The geometries of complexes of ethene with various Lewis acids, as determined from their rotational spectra. Drawings are to scale. In order of increasing non-covalent interaction strength, they are $\mathrm{C}_{2} \mathrm{H}_{4} \cdots \mathrm{HCl}$, $\mathrm{C}_{2} \mathrm{H}_{4} \cdots \mathrm{ClF}, \quad \mathrm{C}_{2} \mathrm{H}_{4} \cdots \mathrm{AgCl}, \quad$ and $\mathrm{C}_{2} \mathrm{H}_{4} \cdots \mathrm{CuCl}$. In each, the Lewis acid lies along the $\mathrm{C}_{2}$ axis of ethene that is perpendicular to the plane of its nuclei. Note the distortion of ethene in the $\mathrm{AgCl}$ and $\mathrm{CuCl}$ complexes.

(b)

( $\mathrm{M}=\mathrm{Cu}$ or $\mathrm{Ag} ; \mathrm{X}=\mathrm{F}, \mathrm{Cl}$, or I). Microwave spectroscopy and $a b$ initio calculations were used to obtain quantitative information about the geometry, electronic structure, and dissociation energy of the complexes. Novick and co-workers have also conducted related investigations of $\mathrm{B} \cdots \mathrm{MX}$, for the interesting case in which B is the hydrogen molecule. ${ }^{16-19}$ When B is ethyne, ethene, or $\mathrm{H}_{2}$, the complexes $\mathrm{B} \cdot \mathrm{MX}$ provide particularly favourable examples of how rotational spectroscopy in combination with high-quality electronic structure calculations can yield precise quantitative details of the geometrical distortion of the molecule $\mathrm{B}$ that accompanies complex formation.

An early conclusion of our investigations of the B $\cdots \mathrm{MX}$ species already mentioned is that their angular geometries are isomorphous with those of the corresponding members of the series of hydrogen-bonded complexes $\mathrm{B} \cdots \mathrm{HX}(\mathrm{X}=\mathrm{F}, \mathrm{Cl}, \mathrm{Br}$, $\mathrm{I}, \mathrm{CN})$. Systematic investigations of the $\mathrm{B} \cdots \mathrm{HX}$ over a number of years led to a set of empirical rules ${ }^{20,21}$ that allowed angular geometries to be rationalized. These rules state that (i) the axis of the HX molecule coincides with the axis of a nonbonding pair of electrons carried by B, (ii) when B has no nonbonding electrons but carries $\pi$-bonding pairs, the axis of the HX molecule lies along the local symmetry axis of a $\pi$ orbital, and (iii) when both non-bonding and $\pi$ bonding electron pairs are present, the non-bonding pair is definitive of the angular geometry. Subsequently, it was shown through a parallel set of investigations of the series $\mathrm{B} \cdot \mathrm{XY}\left(\mathrm{XY}=\mathrm{F}_{2}, \mathrm{Cl}_{2}, \mathrm{Br}_{2}, \mathrm{ClF}\right.$,
$\mathrm{BrCl}$, and $\mathrm{ICl}$ ) that these rules (but modified by substituting HX by XY) also apply to halogen-bonded complexes. ${ }^{22,23}$ In the work reported here, we shall concentrate on rule (ii) and its applicability to $\mathrm{B} \cdots \mathrm{MCl}$ molecules, where $\mathrm{B}$ carries $\pi$ bonding or pseudo- $\pi$ bonding pairs but no non-bonding pairs.

Figure 1(a) shows the angular geometries of the complexes of ethyne with each of $\mathrm{HCl},{ }^{24} \mathrm{ClF}^{25} \mathrm{CuCl},{ }^{13}$ and $\mathrm{AgCl}^{12}$ (all drawn to scale), as determined by rotational spectroscopy. Apart from small distortions of the ethyne subunit by $\mathrm{CuCl}$ and $\mathrm{AgCl}$ (most obvious from the position of the acetylenic $\mathrm{H}$ atoms but also manifest in a small lengthening of the $\mathrm{CC}$ bond), it is clear that the four geometries are isomorphous and that rule (ii) applies. The same conclusion holds for the corresponding set of complexes ${ }^{9,13,26,27}$ with ethene, as shown in Figure 1(b). In each, the $\mathrm{HCl}, \mathrm{ClF}, \mathrm{CuCl}$, or $\mathrm{AgCl}$ molecular axis lies along the symmetry axis of the $\pi$ orbital and is therefore perpendicular to the plane of the ethene nuclei. Again, small distortions of ethene occur for the $\mathrm{CuCl}$ and $\mathrm{AgCl}$ complexes.

Many years ago, Coulson and Moffitt ${ }^{28}$ proposed the pseudo- $\pi$ bonding model for cyclopropane to explain, inter alia, the fact that it behaves like an alkene in some of its reactions. This model invokes $\mathrm{sp}^{3}$ hybridised carbon atoms, with the $\mathrm{CC}$ bonds formed by overlap of the lobes of two $\mathrm{sp}^{3}$ hybrid orbitals on adjacent $C$ atoms to give a "bent," pseudo- $\pi$ bond, as illustrated in Figure 2. Does rule (ii) hold for such pseudo$\pi$ bonds? The experimental geometries of $\left(\mathrm{CH}_{2}\right)_{3} \cdot \cdots \mathrm{HCl}^{29}$ and $\left(\mathrm{CH}_{2}\right)_{3} \cdots \mathrm{ClF}^{30}$ (included in Figure 3 and drawn to scale) show 
(a)

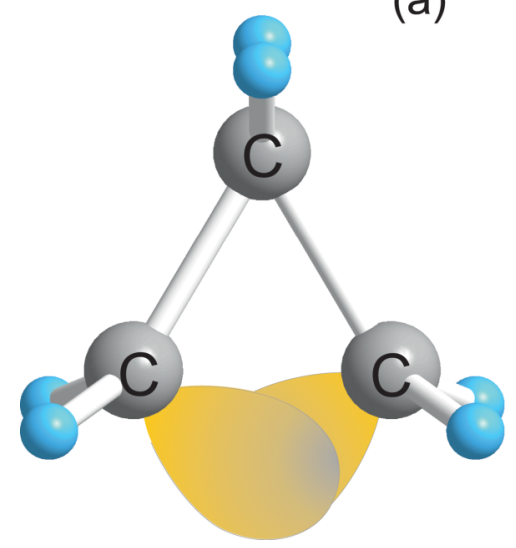

(b)

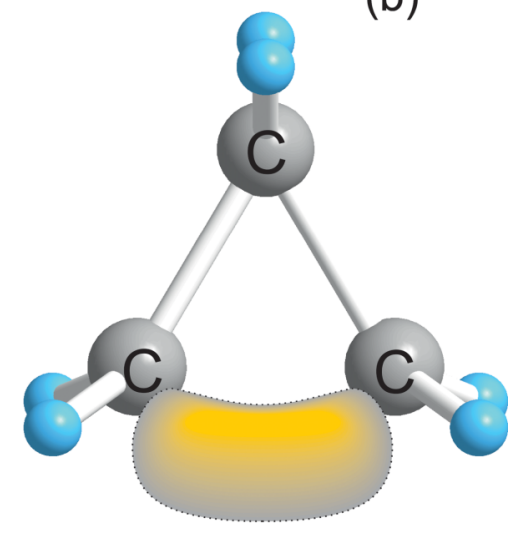

FIG. 2. The Coulson-Moffitt model of electron density in the $\mathrm{C}-\mathrm{C}$ bonds of cyclopropane. Each $\mathrm{C}$ atom is assumed to be $\mathrm{sp}^{3}$ hybridised and each $\mathrm{C}-\mathrm{C}$ bond is formed by overlap of a singly occupied $\mathrm{sp}^{3}$ orbital on two adjacent $\mathrm{C}$ atoms, as in (a), to give the pseudo- $\pi$ bond shown in (b). that it does. The questions to be addressed in this article are as follows: (a) Can the rotational spectra of $\left(\mathrm{CH}_{2}\right)_{3} \cdots \mathrm{CuCl}$ and $\left(\mathrm{CH}_{2}\right)_{3} \cdots \mathrm{AgCl}$ be observed? (b) Are the angular geometries of $\left(\mathrm{CH}_{2}\right)_{3} \cdots \mathrm{CuCl}$ and $\left(\mathrm{CH}_{2}\right)_{3} \cdots \mathrm{AgCl}$ isomorphous with those of their $\mathrm{HCl}$ and $\mathrm{ClF}$ analogues and consistent with rule (ii)? (c) Is the cyclopropane molecule distorted by complexation with the $\mathrm{CuCl}$ or $\mathrm{AgCl}$ molecule and, if so, how does this distortion compare with those observed for ethyne and ethene when they interact with these closed-shell, transition metal halides $\mathrm{MCl}$ ?

\section{EXPERIMENTAL AND THEORETICAL METHODS}

The rotational spectra of cyclopropane $\cdots \mathrm{CuCl}$ and cyclopropane $\cdot \mathrm{AgCl}$ were observed by using a CP-FTMW spectrometer. The spectrometer has been described in detail elsewhere. ${ }^{31,32}$
A gaseous sample mixture was introduced from a single pulsed nozzle oriented perpendicular to the direction of propagation of a microwave excitation pulse introduced from a horn antenna. The gas pulse contained $\sim 1 \% \mathrm{CCl}_{4}$ and $\sim 1 \%$ c- $\mathrm{C}_{3} \mathrm{H}_{6}$ balanced in 6 bar of argon and was flowed over either a silver or copper target rod, as appropriate, before undergoing expansion into a vacuum. The focussed pulse from a Nd:YAG laser ( $\sim 10 \mathrm{~mJ} /$ pulse, $10 \mathrm{~ns}$ duration) was employed to ablate material from the rod target and thus introduce metal into each gaseous sample mixture. Synthetically enriched samples of $1,1-\mathrm{d}_{2}$-cyclopropane (purchased from $\mathrm{CDN}$ isotopes) allowed measurements of spectra of deuterated isotopologues.

The molecular free induction decay (FID) was collected using a second horn antenna positioned opposite to the first. The pulsed nozzle repetition rate was $1.05 \mathrm{~Hz}$, and 8 FIDs, each $20 \mu \mathrm{s}$ in duration, were recorded per nozzle pulse. The final data sets represent time-domain averages of
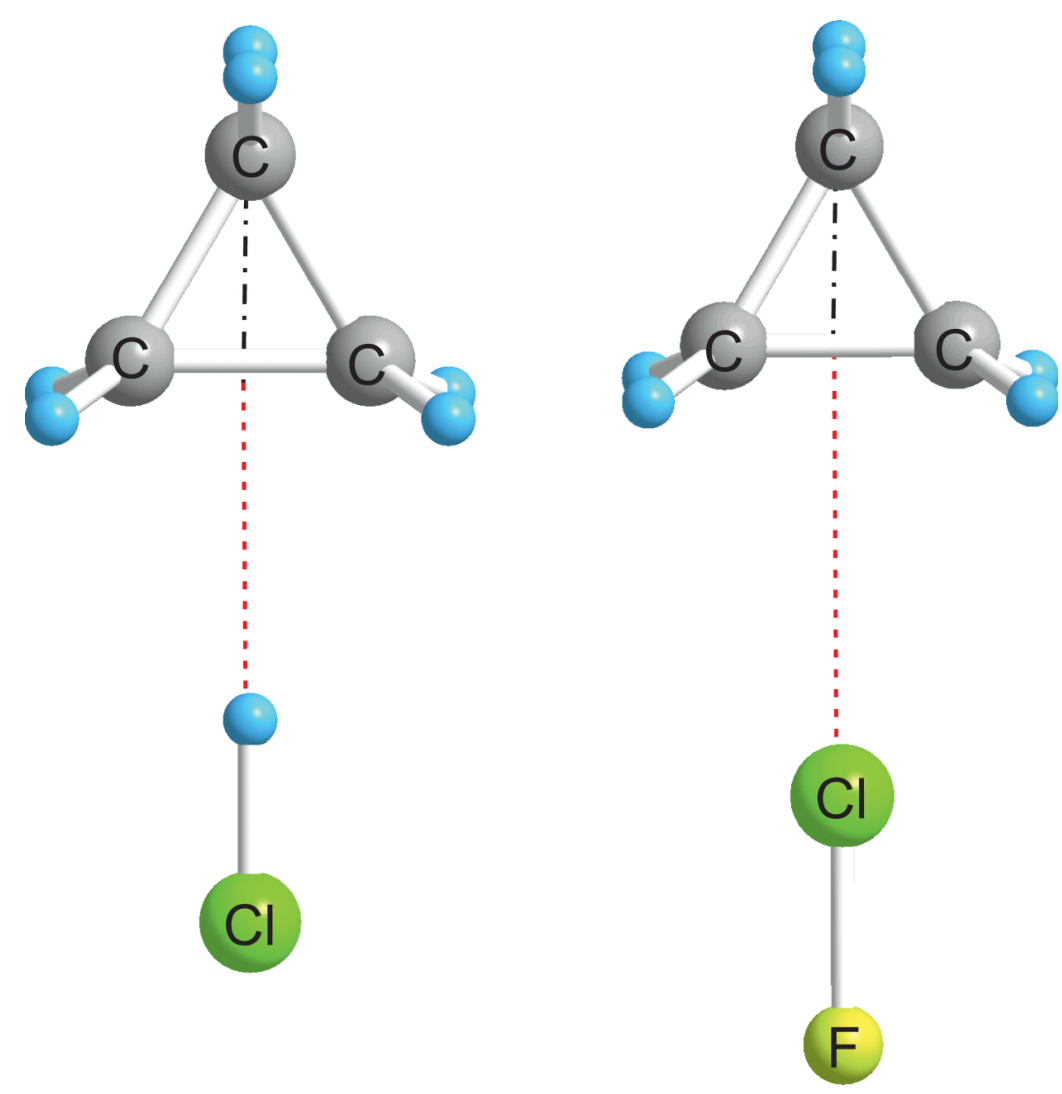

FIG. 3. Geometries (drawn to scale) of the hydrogenbonded and halogen-bonded complexes formed by cyclopropane with $\mathrm{HCl}$ and $\mathrm{ClF}$, respectively. 
multiple FIDs as indicated in brackets: $\left(\mathrm{CH}_{2}\right)_{3} \cdots \mathrm{AgCl}(2.4 \mathrm{M})$, $\left(\mathrm{CD}_{2}\right)\left(\mathrm{CH}_{2}\right)_{2} \cdots \mathrm{AgCl}(1.2 \mathrm{M}),\left(\mathrm{CH}_{2}\right)_{3} \cdots \mathrm{CuCl}(1.8 \mathrm{M})$, and $\left(\mathrm{CD}_{2}\right)\left(\mathrm{CH}_{2}\right)_{2} \cdots \mathrm{CuCl}(1.32 \mathrm{M})$. To obtain frequency-domain spectra of isotopologues containing silver, Fourier transformation was performed with an applied Kaiser-Bessel digital filter. However, for spectra of copper-containing species, it was necessary to apply a high resolution window function ${ }^{14}$ due to increased hyperfine structure. Spectral analysis was performed using the PGOPHER software package. ${ }^{33}$

Geometry optimizations were performed using $\operatorname{CCSD}(\mathrm{T})\left(\mathrm{F} 12^{*}\right)$, a coupled-cluster method with single and double excitations, explicit correlation, and a perturbative treatment of triple excitations. ${ }^{34,35}$ An AVTZ basis set combination was used, by which we mean that aug-cc-pVTZ basis sets were used for the $\mathrm{C}$ and $\mathrm{H}$ atoms, ${ }^{36}$ aug-cc-pV(T+d)Z for $\mathrm{Cl}^{37}$ and aug-cc-pVTZ-PP basis sets for $\mathrm{Cu}$ and $\mathrm{Ag}$, in combination with the ECP-10-MDF and ECP-28-MDF effective core potentials on $\mathrm{Cu}$ and $\mathrm{Ag}$, respectively, to account for scalar relativistic effects. ${ }^{37-39}$ At the optimised geometries, the approximate coupled cluster singles and doubles method $\mathrm{CC} 2^{40}$ was used to compute (unrelaxed) dipole moments. Dissociation energies at the $\operatorname{CCSD}(\mathrm{T})\left(\mathrm{F} 12^{*}\right) / \mathrm{AVTZ}$ level were computed using the counterpoise correction method where, for numerical stability, the singles correction was not included in the correction term. $\operatorname{CCSD}(\mathrm{T})$ calculations were performed us- ing the MOLPRO package, ${ }^{41} \mathrm{CC} 2$ response calculations using the TURBOMOLE package, ${ }^{42}$ and the frozen-core approximation was used throughout.

\section{RESULTS}

\section{A. Determination of spectroscopic constants}

The rotational spectrum observed for each of the isotopologues of $\left(\mathrm{CH}_{2}\right)_{3} \cdots \mathrm{CuCl}$ and $\left(\mathrm{CH}_{2}\right)_{3} \cdots \mathrm{AgCl}$ investigated exhibited only $a$-type transitions. These transitions fell into a pattern characteristic of a nearly prolate, asymmetric rotor, with only those of the type $(J+1)_{n, J+1} \rightarrow J_{n, J}$, where $n=0$, 1 , and 2 , having observable intensity for the most abundant isotopologue in each case. For other isotopologues, those with $K_{-1}=2$ were too weak to observe. Figures 4 and 5 show broadband recordings of the region of the $J=7 \rightarrow 6$ transitions of $\left(\mathrm{CH}_{2}\right)_{3} \cdots \mathrm{CuCl}$ and $\left(\mathrm{CH}_{2}\right)_{3} \cdots \mathrm{AgCl}$, respectively. Transitions with $K_{-1}=1$ differed in intensity from those with $K_{-1}=0$ because of three main effects. The first arises from nuclear-spin statistics. If the geometry of the complex is as predicted from rule (ii) and the Coulson-Moffitt pseudo- $\pi$ model of cyclopropane, that is, if the MX internuclear axis lies along the extension of a median of the cyclopropane triangle and coincides with the principal inertia axis $a$, the operation $C_{2}^{a}$ exchanges three

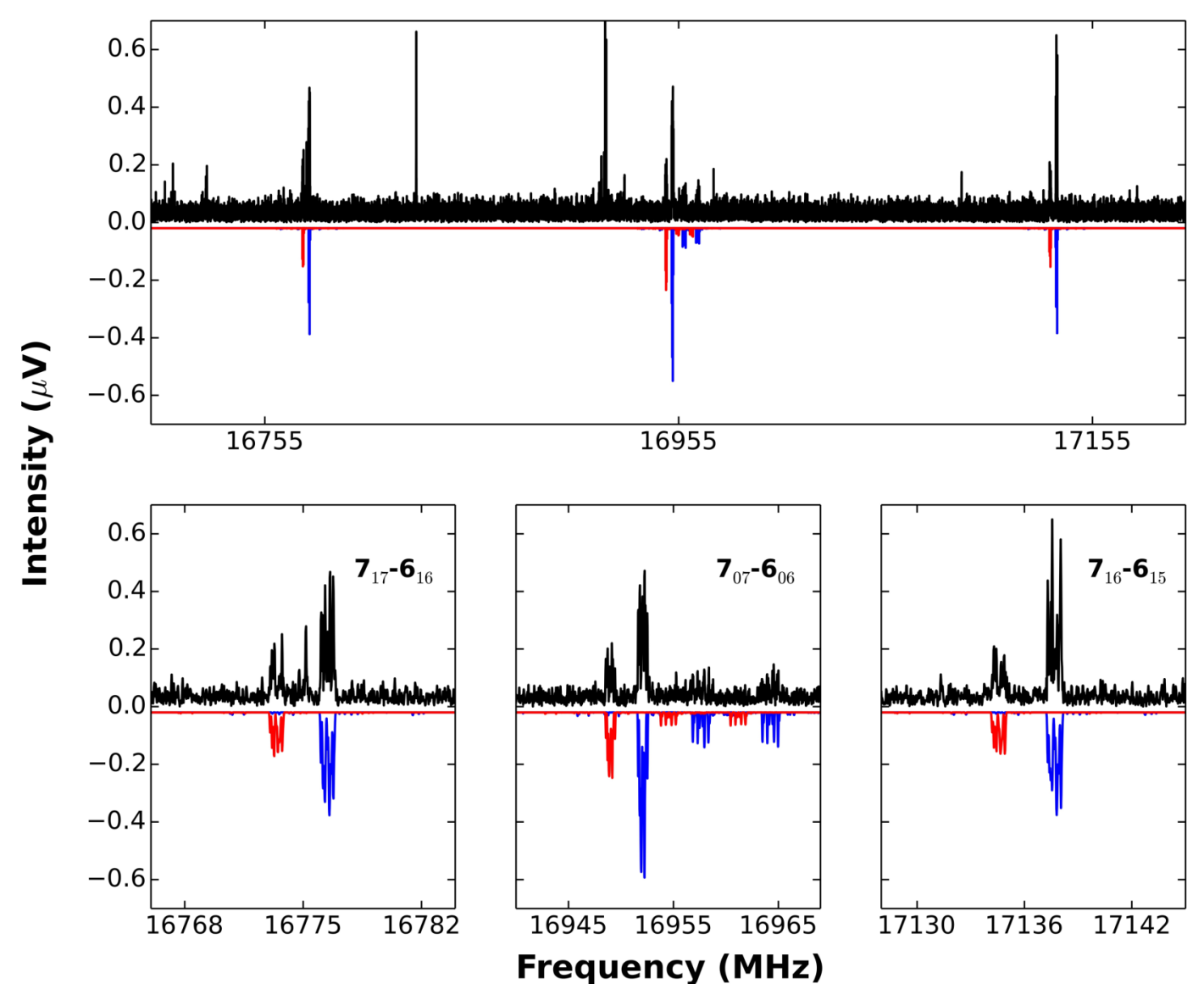

FIG. 4. Broadband rotational spectrum of $\left(\mathrm{CH}_{2}\right)_{3} \cdots \mathrm{CuCl}$ recorded in the region of the $7 \rightarrow 6$ transitions. The downward pointing spectra are those simulated from the experimental spectroscopic constants given in Table I by using the PGOPHER program. The blue spectrum corresponds to the $\left(\mathrm{CH}_{2}\right)_{3} \cdots{ }^{63} \mathrm{Cu}^{35} \mathrm{Cl}$ isotopologue while the red spectrum belongs to $\left(\mathrm{CH}_{2}\right)_{3} \cdot{ }^{65} \mathrm{Cu}^{35} \mathrm{Cl}$. The natural abundances of ${ }^{63} \mathrm{Cu}$ and ${ }^{65} \mathrm{Cu}$ are $69.85 \%$ and $30.85 \%$, respectively. The complicated nuclear quadrupole hyperfine structure arising from the quadrupolar nuclei $\mathrm{Cu}$ and $\mathrm{Cl}$ is evident in each of the three rotational transitions $7_{17} \rightarrow 6_{16}, 7_{07} \rightarrow 6_{06}$ and $7_{16} \rightarrow 6_{15}$ of the lower spectrum, which are shown on an expanded frequency scale. 


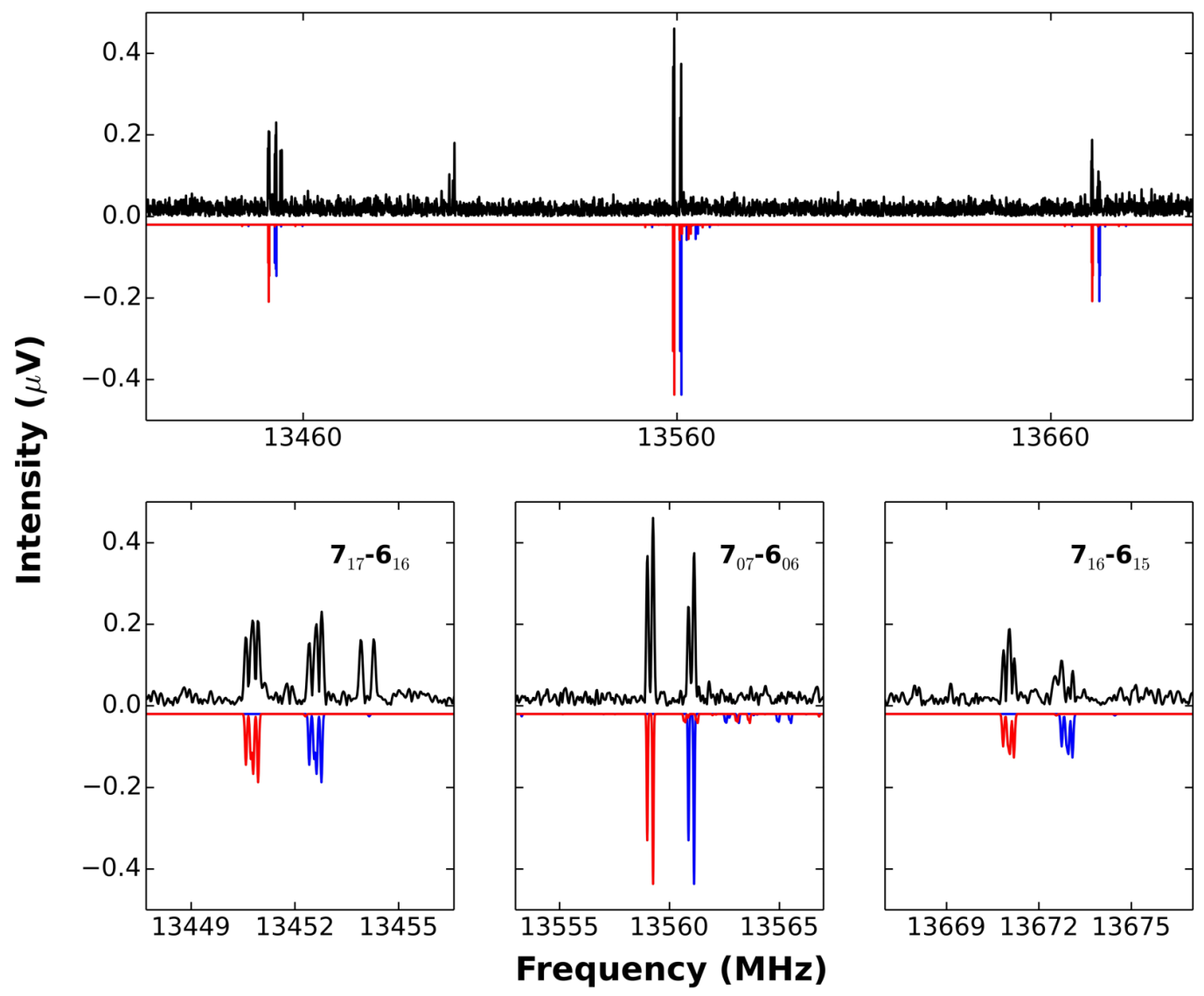

FIG. 5. Broadband rotational spectrum of $\left(\mathrm{CH}_{2}\right)_{3} \cdots \mathrm{AgCl}$ recorded in the region of the $7 \rightarrow 6$ transitions. The downward pointing spectra are simulated from the experimental spectroscopic constants given in Table III by using the PGOPHER program. The blue spectrum corresponds to the $\left(\mathrm{CH}_{2}\right)_{3} \cdots{ }^{107} \mathrm{Ag}^{35} \mathrm{Cl}$ isotopologue while the red spectrum belongs to the $\left(\mathrm{CH}_{2}\right)_{3} \cdot{ }^{109} \mathrm{Ag}^{35} \mathrm{Cl}$. The natural abundances of ${ }^{107} \mathrm{Ag}$ and ${ }^{109} \mathrm{Ag}$ are $51.84 \%$ and $48.16 \%$, respectively. The nuclear quadrupole hyperfine structure arising from the quadrupolar nucleus ${ }^{35} \mathrm{Cl}$ is evident in each of the three rotational transitions $7_{17} \rightarrow 6_{16}, 7_{07} \rightarrow 6_{06}$, and $7_{16} \rightarrow 6_{15}$ in the lower spectrum, which are shown on an expanded frequency scale. The hyperfine structure is simpler in this spectrum than that in Figure 4 because the nuclear electric quadrupole moment of both $\mathrm{Ag}$ isotopes is zero.

pairs of equivalent protons and thereby endows the $K_{-1}=1$ transitions with a nuclear spin statistical weight of 36 relative to a weight of 28 for the $K_{-1}=0$ transitions. Second, the $\mathrm{Cl}$ (and where appropriate $\mathrm{Cu}$ ) nuclear quadrupole hyperfine splitting tends to be larger and better resolved for $K_{-1}=1$ transitions. Finally, the low effective temperature of the supersonic expansion will enhance the population of $K_{-1}=0$ level, if collisional propensity rules permit such transfer of population.

Each rotational transition of $\left(\mathrm{CH}_{2}\right)_{3} \cdots \mathrm{AgCl}$ carried the nuclear quadrupole hyperfine pattern expected for the presence of either a ${ }^{35} \mathrm{Cl}(I=3 / 2)$ or a ${ }^{37} \mathrm{Cl}(I=3 / 2)$ nucleus. For $\left(\mathrm{CH}_{2}\right)_{3} \ldots \mathrm{CuCl}$, the additional quadrupolar nucleus ${ }^{63} \mathrm{Cu}$ $(I=3 / 2)$ or ${ }^{65} \mathrm{Cu}(I=3 / 2)$ led to a more complex hyperfine structure, as is evident from Figure 5 when compared with Figure 4 . Because of the fairly high $J$-value transitions that fall within the frequency range of the spectrometer, the hyperfine structure was not always well resolved. A least-squares fit of the hyperfine frequencies of all observed rotational transitions for each isotopologue was performed by using the program PGOPHER. ${ }^{33}$ The Hamiltonian matrix

$$
H=H_{\mathrm{R}}+H_{\mathrm{Q}(\mathrm{Cl})}+H_{\mathrm{Q}(\mathrm{Cu})}
$$

was constructed in the coupled symmetric-rotor basis $\boldsymbol{I}_{\mathrm{Cl}}+\boldsymbol{J}$ $=\boldsymbol{F}_{1}, \boldsymbol{F}_{1}+\boldsymbol{I}_{\mathrm{Cu}}=\boldsymbol{F}$, and diagonalized in blocks of the quantum number $F$ for each isotopologue of $\left(\mathrm{CH}_{2}\right)_{3} \cdots \mathrm{CuCl}$ investi- gated. For $\left(\mathrm{CH}_{2}\right)_{3} \cdots \mathrm{AgCl}$, the third term is zero. In Eq. (1), $H_{\mathrm{R}}$ is the rotational Hamiltonian appropriate for a semi-rigid asymmetric rotor, for which the Watson A reduction ${ }^{43}$ in the $I_{\mathrm{r}}$ representation was chosen, and $H_{\mathrm{Q}(\mathrm{X})}=-\frac{1}{6} Q_{\alpha \beta}^{\mathrm{X}} V_{\alpha \beta}^{\mathrm{X}}(\alpha$ and $\beta$ to be permuted over $a, b$, and $c$ ) accounts for the nuclear quadrupole coupling energy arising from the interaction of the nuclear electric quadrupole tensor $Q_{\alpha \beta}^{\mathrm{X}}$ of nucleus $\mathrm{X}$ with the electric field gradient (e.f.g.) tensor $V_{\alpha \beta}^{\mathrm{X}}$ at that nucleus. Only two $\left(\Delta_{J}\right.$ and $\left.\Delta_{J K}\right)$ of the five quartic centrifugal distortion constants were determinable (i.e., differed from zero by more than their standard error) for even the most abundant isotopologues because of the limited range of $a$ type transitions available and the fact that all isotopologues are nearly prolate, asymmetric rotors exhibiting only $a$-type transitions. Indeed, except for the most abundant isotopologues of $\left(\mathrm{CH}_{2}\right)_{3} \cdots \mathrm{CuCl}$ and of $\left(\mathrm{CH}_{2}\right)_{3} \cdots \mathrm{AgCl}$, insufficient transitions were available to determine even $\Delta_{J}$ and $\Delta_{J K}$ satisfactorily. Consequently, these constants were assumed unchanged from those of the most abundant isotopologue in each case. Only one diagonal element, namely, $\chi_{a a}(\mathrm{X})$, of each nuclear quadrupole coupling tensor $\chi_{\alpha \beta}(\mathrm{X})=-\left(e Q^{\mathrm{X}} / h\right) V_{\alpha \beta}^{\mathrm{X}}$ was necessary to produce fits with a rms deviation of magnitude similar to the estimated accuracy of frequency measurement. This implies that each anisotropy $\chi_{b b}(\mathrm{X})-\chi_{c c}(\mathrm{X})$ is zero within experimental error. This observation is readily 
TABLE I. Ground-state spectroscopic constants determined for isotopologues of $\left(\mathrm{CH}_{2}\right)_{3} \cdots \mathrm{CuCl}$ observed in natural abundance.

\begin{tabular}{lccc}
\hline \hline Spectroscopic constant & $\left({ }^{12} \mathrm{CH}_{2}\right)_{3} \cdots{ }^{63} \mathrm{Cu}^{35} \mathrm{Cl}$ & $\left({ }^{12} \mathrm{CH}_{2}\right)_{3} \cdots{ }^{65} \mathrm{Cu}^{35} \mathrm{Cl}$ & $\left({ }^{12} \mathrm{CH}_{2}\right)_{3} \cdot{ }^{63} \mathrm{Cu}^{37} \mathrm{Cl}$ \\
\hline$A_{0} / \mathrm{MHz}$ & $18059(17)^{\mathrm{a}}$ & $18058(19)$ & $18058(20)$ \\
$B_{0} / \mathrm{MHz}$ & $1237.15080(43)$ & $1236.92315(40)$ & $1206.8128(14)$ \\
$C_{0} / \mathrm{MHz}$ & $1185.54119(42)$ & $1185.32951(52)$ & $1157.9330(12)$ \\
$\Delta_{J K} / \mathrm{kHz}^{\mathrm{b}}$ & $2.40(17)$ & {$[2.40]$} & {$[2.40]$} \\
$\Delta_{J} / \mathrm{kHz}$ & $0.1329(51)$ & {$[0.1329]$} & {$[0.1329]$} \\
$\chi_{a a}(\mathrm{Cl}) / \mathrm{MHz}$ & $-24.252(69)$ & $-24.50(16)$ & $-18.68(21)$ \\
$\chi_{a a}(\mathrm{Cu}) / \mathrm{MHz}$ & $57.307(85)$ & $52.97(22)$ & $57.69(39)$ \\
$P_{a} / \mathrm{u} \AA^{2 c}$ & $403.401(13)$ & $403.476(15)$ & $413.616(16)$ \\
$P_{b} / \mathrm{u} \AA^{2}$ & $22.884(13)$ & $22.885(15)$ & $22.832(16)$ \\
$P_{c} / \mathrm{u} \AA^{2}$ & $5.101(13)$ & $5.101(15)$ & $5.154(16)$ \\
$N^{\mathrm{d}}$ & 91 & 32 & 13 \\
$\sigma_{\mathrm{rms}} / \mathrm{kHz}^{\mathrm{e}}$ & 10.8 & 10.7 & 10.1 \\
\hline \hline
\end{tabular}

\footnotetext{
${ }^{a}$ Numbers in parentheses are one standard deviation in units of the last significant digits.

${ }^{\mathrm{b}}$ Centrifugal distortion constants in square brackets are fixed in the fit at values unchanged from the most abundant isotopologue.

${ }^{\mathrm{c}}$ Planar moments $P_{a}$, etc. are defined in Eq. (2).

${ }^{\mathrm{d}} N$ is the number of hyperfine frequencies included in the fit.

${ }^{\mathrm{e}}$ Root-mean square deviation of the fit.
}

understood by considering the experimental values $\chi_{b b}(\mathrm{Cl})$ $-\chi_{c c}(\mathrm{Cl})=0.09(14)$ and $0.47(1) \mathrm{MHz}$ determined for the complexes $\left(\mathrm{CH}_{2}\right)_{3} \cdots \mathrm{H}^{35} \mathrm{Cl}$ and $\left(\mathrm{CH}_{2}\right)_{3} \cdots{ }^{35} \mathrm{ClF}$, respectively. ${ }^{29,30}$ It will be shown in Section III B that $\left(\mathrm{CH}_{2}\right)_{3} \cdots \mathrm{CuCl}$ and $\left(\mathrm{CH}_{2}\right)_{3} \cdots \mathrm{AgCl}$ have geometries isomorphous with those of $\left(\mathrm{CH}_{2}\right)_{3} \cdots \mathrm{HCl}$ and $\left(\mathrm{CH}_{2}\right)_{3} \cdots \mathrm{ClF}$, which are displayed in Figure 3. Moreover, the distance of $\mathrm{Cl}$ from the centre of the cyclopropane ring is less in both of these complexes than in $\left(\mathrm{CH}_{2}\right)_{3} \cdots \mathrm{AgCl}$, so it is expected that $\chi_{b b}(\mathrm{Cl})-\chi_{c c}(\mathrm{Cl})$ will be even closer to zero in $\left(\mathrm{CH}_{2}\right)_{3} \cdots \mathrm{AgCl}$. The distance of $\mathrm{Cu}$ from the centre of the ring in $\left(\mathrm{CH}_{2}\right)_{3} \cdots \mathrm{CuCl}$ is only slightly less than that of $\mathrm{Cl}$ in $\left(\mathrm{CH}_{2}\right)_{3} \cdots \mathrm{ClF}$ and therefore $\chi_{b b}(\mathrm{Cu})$ $-\chi_{c c}(\mathrm{Cu})$ is also likely to be very small. Accordingly, $\chi_{b b}(\mathrm{X})$ $-\chi_{c c}(\mathrm{X})$ was set to zero in all fits.

Assignments and measured frequencies of nuclear hyperfine components of all observed rotational transitions, together with residuals and spectroscopic constants from the final cycle of the PGOPHER fits, are available as the supplementary material ${ }^{44}$ for each of the isotopologues of $\left(\mathrm{CH}_{2}\right)_{3} \cdots \mathrm{CuCl}$ and $\left(\mathrm{CH}_{2}\right)_{3} \cdots \mathrm{AgCl}$ investigated. Table I contains the spectroscopic constants thus determined for the isotopologues of $\left(\mathrm{CH}_{2}\right)_{3} \ldots \mathrm{CuCl}$ measured in natural abundance, namely, $\left(\mathrm{CH}_{2}\right)_{3} \cdot{ }^{63} \mathrm{Cu}^{35} \mathrm{Cl},\left(\mathrm{CH}_{2}\right)_{3} \cdot{ }^{65} \mathrm{Cu}^{35} \mathrm{Cl}$, and $\left(\mathrm{CH}_{2}\right)_{3} \cdot{ }^{63} \mathrm{Cu}^{37} \mathrm{Cl}$. In order to determine the orientation of the cyclopropane subunit in the complex, it was necessary to use an isotopically enriched sample of $\left(\mathrm{CH}_{2}\right)_{2}\left(\mathrm{CD}_{2}\right)$. The spectroscopic constants of $\left(\mathrm{CH}_{2}\right)_{3} \cdots \mathrm{CuCl}$ isotopologues containing $\left(\mathrm{CH}_{2}\right)_{2}\left(\mathrm{CD}_{2}\right)$ are given in Table II, namely, $\left({ }^{\mathrm{B}} \mathrm{CD}_{2}\right)\left(\mathrm{CH}_{2}\right)_{2} \cdots{ }^{63} \mathrm{Cu}^{35} \mathrm{Cl},\left({ }^{\mathrm{B}} \mathrm{CD}_{2}\right)\left(\mathrm{CH}_{2}\right)_{2} \ldots{ }^{65} \mathrm{Cu}^{35} \mathrm{Cl}$, $\left({ }^{\mathrm{F}} \mathrm{CD}_{2}\right)\left(\mathrm{CH}_{2}\right)_{2} \cdots{ }^{63} \mathrm{Cu}^{35} \mathrm{Cl}, \quad\left({ }^{\mathrm{F}} \mathrm{CD}_{2}\right)\left(\mathrm{CH}_{2}\right)_{2} \cdots{ }^{65} \mathrm{Cu}^{35} \mathrm{Cl}$, and $\left({ }^{\mathrm{F}} \mathrm{CD}_{2}\right)\left(\mathrm{CH}_{2}\right)_{2} \cdots{ }^{63} \mathrm{Cu}^{37} \mathrm{Cl}$, where the nomenclature anticipates the determined geometry of this complex, which is of the form displayed in Figure 6. Thus, a superscript B on $\mathrm{C}$ indicates that the $\mathrm{D}_{2}$ substitution is at the unique $\mathrm{C}$

TABLE II. Ground-state spectroscopic constants of $\left(\mathrm{CH}_{2}\right)_{3} \cdots \mathrm{CuCl}$ isotopologues containing $\mathrm{CD}_{2}$ groups at the front or back of the cyclopropane ring. ${ }^{\mathrm{a}}$

\begin{tabular}{|c|c|c|c|c|c|}
\hline $\begin{array}{l}\text { Spectroscopic } \\
\text { constant }\end{array}$ & $\left(\mathrm{CH}_{2}\right)_{2}\left({ }^{\mathrm{F}} \mathrm{CD}_{2}\right) \cdots{ }^{63} \mathrm{Cu}^{35} \mathrm{Cl}$ & $\left(\mathrm{CH}_{2}\right)_{2}\left({ }^{\mathrm{F}} \mathrm{CD}_{2}\right) \cdots{ }^{63} \mathrm{Cu}^{37} \mathrm{Cl}$ & $\left(\mathrm{CH}_{2}\right)_{2}\left({ }^{\mathrm{F}} \mathrm{CD}_{2}\right) \cdots{ }^{65} \mathrm{Cu}^{35} \mathrm{Cl}$ & $\left(\mathrm{CH}_{2}\right)_{2}\left({ }^{\mathrm{B}} \mathrm{CD}_{2}\right) \cdots{ }^{63} \mathrm{Cu}^{35} \mathrm{Cl}$ & $\left(\mathrm{CH}_{2}\right)_{2}\left({ }^{\mathrm{B}} \mathrm{CD}_{2}\right) \cdots{ }^{65} \mathrm{Cu}^{35} \mathrm{Cl}$ \\
\hline$A_{0} / \mathrm{MHz}$ & $15252.8(49)$ & $15252(18)$ & $15252(20)$ & $17040(12)^{\mathrm{b}}$ & $17039(15)$ \\
\hline$B_{0} / \mathrm{MHz}$ & $1217.56791(29)$ & $1187.96330(53)$ & $1217.29097(42)$ & $1159.44321(29)$ & $1159.12242(36)$ \\
\hline$C_{0} / \mathrm{MHz}$ & $1162.83757(30)$ & $1135.82484(48)$ & $1162.58231(40)$ & $1118.17772(26)$ & $1117.87261(32)$ \\
\hline$\Delta_{J K} / \mathrm{kHz}^{\mathrm{c}}$ & {$[2.40]$} & {$[2.40]$} & {$[2.40]$} & {$[2.40]$} & {$[2.40]$} \\
\hline$\Delta_{J} / \mathrm{kHz}^{\mathrm{c}}$ & [0.1329] & [0.1329] & [0.1329] & [0.1329] & [0.1329] \\
\hline$\chi_{a a}(\mathrm{Cl}) / \mathrm{MHz}$ & $-24.21(10)$ & $-19.30(30)$ & $-24.24(9)$ & $-24.30(15)$ & $-24.12(12)$ \\
\hline$\chi_{a a}(\mathrm{Cu}) / \mathrm{MHz}$ & $57.08(26)$ & $53.32(18)$ & $52.90(14)$ & $57.32(38)$ & $52.75(20)$ \\
\hline$P_{a} / \mathrm{u} \AA^{2 \mathrm{~d}}$ & $408.273(5)$ & $418.612(20)$ & $408.367(22)$ & $429.094(10)$ & $429.215(13)$ \\
\hline$P_{b} / \mathrm{u} \AA^{2}$ & $26.335(5)$ & $26.332(20)$ & $26.336(22)$ & $22.872(10)$ & $22.874(13)$ \\
\hline$P_{c} / \mathrm{u} \AA^{2}$ & $6.799(5)$ & $6.804(20)$ & $6.799(22)$ & $6.786(10)$ & $6.786(13)$ \\
\hline$N^{\mathrm{e}}$ & 77 & 27 & 44 & 67 & 45 \\
\hline$\sigma_{\mathrm{rms}} / \mathrm{kHz}^{\mathrm{f}}$ & 9.7 & 10.0 & 9.6 & 9.3 & 9.7 \\
\hline
\end{tabular}

$\overline{\bar{a}}$ Superscripts $\mathrm{F}$ and $\mathrm{B}$ on the $\mathrm{CD}_{2}$ group indicate whether the $\mathrm{D}$ atoms are attached to one of the two equivalent $\mathrm{C}$ atoms closest to the metal atom $\mathrm{M}$ or to the $\mathrm{C}$ atom on the $\mathrm{C}_{2}$ axis (see Figure 6).

${ }^{\mathrm{b}}$ Numbers in parentheses are one standard deviation in units of the last significant digits.

${ }^{\mathrm{c}}$ Centrifugal distortion constants in square brackets are fixed in the fit at values unchanged from the most abundant isotopologue.

${ }^{\mathrm{d}}$ Planar moments $P_{a}$, etc. are defined in Eq. (2).

${ }^{\mathrm{e}} N$ is the number of hyperfine frequencies included in the fit.

${ }^{\mathrm{f}}$ Root-mean square deviation of the fit. 

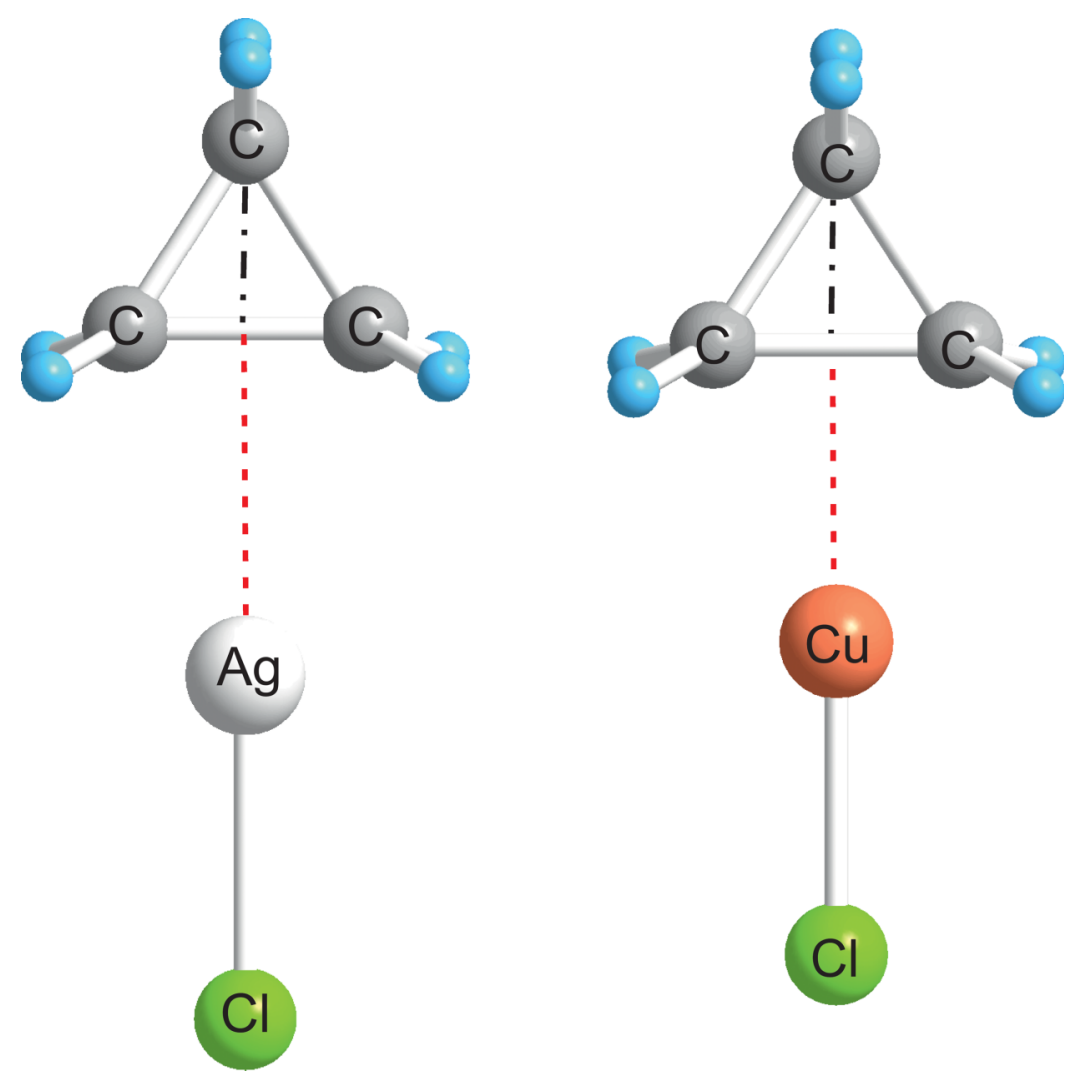

FIG. 6. The angular geometry of (a) $\left(\mathrm{CH}_{2}\right)_{3} \cdots \mathrm{AgCl}$ and (b) $\left(\mathrm{CH}_{2}\right)_{3} \cdots \mathrm{CuCl}$ drawn to scale. The three $\mathrm{C}$ atoms, the metal atom $\mathrm{M}$, and the $\mathrm{Cl}$ atom are coplanar. The atoms ${ }^{\mathrm{B}} \mathrm{C}, \mathrm{M}$, and $\mathrm{Cl}$ lie on the principal inertia axis $a$ in both molecules (superscript $\mathrm{F}$ refers to front $\mathrm{C}$ atoms, i.e., those closest to the metal, while the superscript $\mathrm{B}$ refers to the back, unique $\mathrm{C}$ atom). The $\mathrm{MCl}$ molecule lies along the local symmetry axis of the pseudo- $\pi$ electron density shown schematically in Figure 2. The bond lengths and angles determined by fitting the principal moments of inertia for 8 isotopologues of each of $\left(\mathrm{CH}_{2}\right)_{3} \cdots \mathrm{CuCl}$ and $\left(\mathrm{CH}_{2}\right)_{3} \cdots \mathrm{CuCl}$ are recorded in Table VII. The most notable feature of each geometry is the significant distortion of the ${ }^{\mathrm{F}} \mathrm{C}-{ }^{\mathrm{F}} \mathrm{C}$ bond and a concomitant contraction of the two ${ }^{\mathrm{B}} \mathrm{C}-{ }^{\mathrm{F}_{\mathrm{C}}} \mathrm{C}$ bonds on complex formation. atom, i.e., the $\mathrm{C}$ atom on the $a$-axis and remote from $\mathrm{CuCl}$. Correspondingly, superscript $\mathrm{F}$ on $\mathrm{C}$ delineates an isotopologue in which the $\mathrm{D}_{2}$ substitution is at one of the two equivalent $\mathrm{C}$ atoms nearest the $\mathrm{CuCl}$ subunit. The set of spectroscopic constants determined for the corresponding isotopologues of $\left(\mathrm{CH}_{2}\right)_{3} \cdots \mathrm{AgCl}$ are in Tables III and IV. Thus, Table III deals with $\left(\mathrm{CH}_{2}\right)_{3} \cdot{ }^{107} \mathrm{Ag}^{35} \mathrm{Cl},\left(\mathrm{CH}_{2}\right)_{3} \cdot{ }^{109} \mathrm{Ag}^{35} \mathrm{Cl}$, $\left(\mathrm{CH}_{2}\right)_{3} \cdot{ }^{107} \mathrm{Ag}^{37} \mathrm{Cl}$, and $\left(\mathrm{CH}_{2}\right)_{3} \cdot{ }^{109} \mathrm{Ag}^{37} \mathrm{Cl}$, while Table IV contains the various $\left(\mathrm{CH}_{2}\right)_{2}\left(\mathrm{CD}_{2}\right) \cdots \mathrm{AgCl}$ species. The values of the rms deviation of the fits $\sigma_{\text {rms }}$ (included in Tables I-IV) are generally of the same order as the estimated accuracy of frequency measurement $(15-20 \mathrm{kHz})$, indicating that the chosen Hamiltonian of Eq. (1) was satisfactory. The rotational constants $A_{0}$ are less precisely determined than the other rotational constants because only $a$-type, Rbranch transitions of nearly prolate asymmetric rotors were available.

\section{B. Symmetry and geometry of $\left(\mathrm{CH}_{2}\right)_{3} \cdots \mathrm{CuCl}$ and $\left(\mathrm{CH}_{2}\right)_{3} \ldots \mathrm{AgCl}$}

\section{Molecular symmetry}

There are several observations about the spectroscopic constants of both $\left(\mathrm{CH}_{2}\right)_{3} \cdots \mathrm{CuCl}$ and $\left(\mathrm{CH}_{2}\right)_{3} \cdots \mathrm{AgCl}$ that allow

TABLE III. Ground-state spectroscopic constants determined for isotopologues of $\left(\mathrm{CH}_{2}\right)_{3} \cdots \mathrm{AgCl}$ observed in natural abundance.

\begin{tabular}{lcccc}
\hline \hline $\begin{array}{l}\text { Spectroscopic } \\
\text { constant }\end{array}$ & $\left({ }^{12} \mathrm{CH}_{2}\right)_{3} \cdots{ }^{107} \mathrm{Ag}^{35} \mathrm{Cl}$ & $\left({ }^{12} \mathrm{CH}_{2}\right)_{3} \cdots{ }^{109} \mathrm{Ag}^{35} \mathrm{Cl}$ & $\left({ }^{12} \mathrm{CH}_{2}\right)_{3} \cdots{ }^{107} \mathrm{Ag}^{37} \mathrm{Cl}$ & $\left({ }^{12} \mathrm{CH}_{2}\right){ }_{3} \cdots{ }^{109} \mathrm{Ag}^{37} \mathrm{Cl}$ \\
\hline$A_{0} / \mathrm{MHz}$ & $18495.501(10)^{\mathrm{a}}$ & $18493.480(38)$ & $18494(20)$ & $18494(19)$ \\
$B_{0} / \mathrm{MHz}$ & $984.56142(39)$ & $984.42325(32)$ & $962.04580(47)$ & $961.94899(50)$ \\
$C_{0} / \mathrm{MHz}$ & $953.08595(41)$ & $952.95698(30)$ & $931.97444(51)$ & $931.88257(46)$ \\
$\Delta_{J K} / \mathrm{kHz}^{\mathrm{b}}$ & $3.665(92)$ & {$[3.665]$} & {$[3.665]$} & {$[3.665]$} \\
$\Delta_{J} / \mathrm{kHz}$ & $0.0991(23)$ & {$[0.0991]$} & {$[0.0991]$} & {$[0.0991]$} \\
$\chi_{a a}(\mathrm{Cl}) / \mathrm{MHz}$ & $-31.26(26)$ & $-31.18(26)$ & $-25.17(54)$ & $-25.57(47)$ \\
$P_{a} / \mathrm{u} \AA^{2} \mathrm{c}$ & $508.11634(15)$ & $508.18675(12)$ & $520.128(15)$ & $520.181(14)$ \\
$P_{b} / \mathrm{u} \AA^{2}$ & $22.13805(15)$ & $22.13940(12)$ & $22.138(15)$ & $22.139(14)$ \\
$P_{c} / \mathrm{u} \AA^{2}$ & $5.18633(15)$ & $5.1879(12)$ & $5.188(15)$ & $5.188(14)$ \\
$N^{\mathrm{d}}$ & 34 & 33 & 14 & 14 \\
$\sigma_{\mathrm{rms}} / \mathrm{kHz}$ & 10.3 & 9.4 & 9.7 & 9.6 \\
\hline \hline
\end{tabular}

\footnotetext{
${ }^{a}$ Numbers in parentheses are one standard deviation in units of the last significant digits.

${ }^{\mathrm{b}}$ Centrifugal distortion constants in square brackets are fixed at values unchanged from the most abundant isotopologue.

${ }^{\mathrm{c}}$ Planar moments $P_{a}$, etc. are defined in Eq. (2).

${ }^{\mathrm{d}} N$ is the number of hyperfine frequencies included in the fit.

${ }^{\mathrm{e}}$ Root-mean square deviation of the fit.
} 
TABLE IV. Ground-state spectroscopic constants of cyclopropane $\cdots \mathrm{AgCl}$ isotopologues containing $\mathrm{CD}_{2}$ groups at the front or back of the cyclopropane ring. ${ }^{\mathrm{a}}$

\begin{tabular}{lcccc}
\hline \hline Spectroscopic constant & $\left(\mathrm{CH}_{2}\right)_{2}\left({ }^{\mathrm{F}} \mathrm{CD}_{2}\right) \cdots{ }^{107} \mathrm{Ag}^{35} \mathrm{Cl}$ & $\left(\mathrm{CH}_{2}\right)_{2}\left({ }^{\mathrm{F}} \mathrm{CD}_{2}\right) \cdots{ }^{109} \mathrm{Ag}^{35} \mathrm{Cl}$ & $\left(\mathrm{CH}_{2}\right)_{2}\left({ }^{\mathrm{B}} \mathrm{CD}_{2}\right) \cdots{ }^{107} \mathrm{Ag}^{35} \mathrm{Cl}^{3}$ & $\left(\mathrm{CH}_{2}\right)_{2}\left({ }^{\mathrm{B}} \mathrm{CD}_{2}\right) \cdots{ }^{109} \mathrm{Ag}^{35} \mathrm{Cl}$ \\
\hline$A_{0} / \mathrm{MHz}$ & $15675(17)^{\mathrm{b}}$ & $15674(19)$ & $17466(30)$ & $17466(32)$ \\
$B_{0} / \mathrm{MHz}$ & $968.31981(43)$ & $968.15711(41)$ & $925.40020(48)$ & $925.2180(14)$ \\
$C_{0} / \mathrm{MHz}$ & $934.96719(45)$ & $934.81285(39)$ & $900.26347(50)$ & $900.0888(12)$ \\
$\Delta_{J K} / \mathrm{kHz}^{\mathrm{c}}$ & {$[3.665]$} & {$[3.665]$} & {$[3.665]$} & {$[3.665]$} \\
$\Delta_{J} / \mathrm{kHz}$ & {$[0.0991]$} & {$[0.0991]$} & {$[0.0991]$} & {$[0.0991]$} \\
$\chi_{a a}(\mathrm{Cl}) /(\mathrm{MHz})$ & $-31.06(19)$ & $-31.41(27)$ & $-31.52(38)$ & $-30.43(52)$ \\
$P_{a} / \mathrm{u} \AA^{2 \mathrm{~d}}$ & $515.101(17)$ & $515.188(20)$ & $539.275(25)$ & $539.383(27)$ \\
$P_{b} / \mathrm{u} \mathrm{\AA} \AA^{2}$ & $25.429(17)$ & $25.431(20)$ & $22.092(25)$ & $22.092(27)$ \\
$P_{c} / \mathrm{u} \mathrm{\AA} \AA^{2}$ & $6.812(17)$ & $6.812(20)$ & $6.843(25)$ & $6.843(27)$ \\
$N^{\mathrm{e}}$ & 24 & 25 & 22 & 13 \\
$\sigma_{\mathrm{rms}} / \mathrm{kHz}^{\mathrm{f}}$ & 9.6 & 9.4 & 9.8 & 10.4 \\
\hline
\end{tabular}

$\overline{\bar{a}}$ Superscripts $\mathrm{F}$ and $\mathrm{B}$ on the $\mathrm{CD}_{2}$ group indicate whether the $\mathrm{D}$ atoms are attached to one of the two equivalent $\mathrm{C}$ atoms closest to the metal atom $\mathrm{M}$ or to the $\mathrm{C}$ atom on the $\mathrm{C}_{2}$ axis (see Figure 6).

${ }^{b}$ Numbers in parentheses are one standard deviation in units of the last significant digits.

${ }^{c}$ Centrifugal distortion constants in square brackets are fixed in the fit at values unchanged from the most abundant isotopologue.

${ }^{\mathrm{d}}$ Planar moments $P_{a}$, etc. are defined in Eq. (2).

${ }^{\mathrm{e}} N$ is the number of hyperfine frequencies included in the fit.

${ }^{\mathrm{f}}$ Root-mean square deviation of the fit.

the symmetries and angular geometries of the molecules to be established. These observations are common for both species and therefore, where appropriate, the two can be treated together. Once these qualitative aspects of geometry are established, attention will turn to the quantitative details, as described in Section III B 2.

Although the rotational constants $A_{0}$ are not as precisely determined as the rotational constants $B_{0}$ and $C_{0}$ (see Tables I-IV), we note that $A_{0}$ is similar in magnitude for each of the molecules containing the most abundant isotopologue of cyclopropane, $\left({ }^{12} \mathrm{CH}_{2}\right)_{3}$. Moreover, $A_{0}$ is invariant for these isotopologues within experimental error under isotopic substitution at both $\mathrm{M}$ and $\mathrm{Cl}$. This observation requires that both $\mathrm{M}$ and $\mathrm{Cl}$ lie on (or very close to) the principal inertia axis $a$, suggesting that the $a$ axis lies in the plane of the three $\mathrm{C}$ atoms of cyclopropane and that the centre of mass of the cyclopropane subunit lies on the $a$ axis. However, while the mean value $A_{0}=18058(10) \mathrm{MHz}$ for the three $\left({ }^{12} \mathrm{CH}_{2}\right)_{3}$ containing isotopologues when $\mathrm{M}=\mathrm{Cu}$ is large and reasonably close to $B_{0}=20093.3348(33) \mathrm{MHz}$ of the most abundant form of free cyclopropane, it is significantly smaller (by $2035 \mathrm{MHz}$ ) (see Table V, in which are collected some properties of various isotopologues of cyclopropane, $\mathrm{CuCl}$, and $\mathrm{AgCl}$ to be invoked here, including ground-state rotational constants). ${ }^{45-47}$ Similar conclusions hold for the $A_{0}$ values of the $\left({ }^{12} \mathrm{CH}_{2}\right)_{3} \cdots \mathrm{AgCl}$ isotopologues, which are also invariant under substitution at $\mathrm{Ag}$ and $\mathrm{Cl}$ and for which the mean value is $A_{0}=18494(10) \mathrm{MHz}$, reduced by $1600 \mathrm{MHz}$ from that of free $\left({ }^{12} \mathrm{CH}_{2}\right)_{3}$ (see Tables III-V).

The observations in the foregoing paragraph suggest, but do not prove, that both molecules have a geometry of the type shown in Figure 6, i.e., with the $\mathrm{M}$ and $\mathrm{Cl}$ atoms and the cyclopropane centre of mass lying on the $a$ axis. However, the fact that the principal moment of inertia $I_{a}^{0}$ increases significantly from the corresponding quantity in free cyclopropane (see Table V) suggests that the front $\mathrm{C}-\mathrm{C}$ bond of the cyclopropane ring expands on complex formation for both $\mathrm{M}=\mathrm{Cu}$ and $\mathrm{M}=\mathrm{Ag}$, but more so in the case of $\mathrm{Cu}$. This conclusion is reinforced by examination of $A_{0}$ values for the isotopologues $\left({ }^{\mathrm{B}} \mathrm{CD}_{2}\right)\left(\mathrm{CH}_{2}\right)_{2} \cdots \mathrm{MCl}$, which also show

TABLE V. Some properties of isotopologues of cyclopropane, $\mathrm{CuCl}$, and $\mathrm{AgCl}$.

\begin{tabular}{lcccc}
\hline \hline Property & $\left({ }^{12} \mathrm{CH}_{2}\right)_{3}{ }^{\mathrm{a}}$ & $\left({ }^{12} \mathrm{CH}_{2}\right)_{2}\left({ }^{12} \mathrm{CD}_{2}\right)^{\mathrm{b}}$ & ${ }^{63} \mathrm{Cu}^{35} \mathrm{Cl}^{\mathrm{c}}$ & ${ }^{107} \mathrm{Ag}^{35} \mathrm{Cl}^{\mathrm{c}}$ \\
\hline$A_{0} / \mathrm{MHz}$ & $20093.3348(28)$ & $18835.662(18)$ & $\ldots$ & $\ldots$ \\
$B_{0} / \mathrm{MHz}$ & $20093.3348(28)$ & $16370.2703(70)$ & $5328.54998(23)$ & $3678.0430(4)$ \\
$C_{0} / \mathrm{MHz}$ & $12555.7498(18)$ & $11409.2285(67)$ & $5328.54998(23)$ & $3678.0430(4)$ \\
$P_{a} / \mathrm{u} \AA^{2}$ & 20.125401 & 24.168212 & $\ldots$ & $\ldots$ \\
$P_{b} / \mathrm{u} \AA^{2}$ & 20.125401 & 20.1274213 & $\ldots$ & $\ldots$ \\
$P_{c} / \mathrm{u} \AA^{2}$ & 5.0261732 & 6.7035446 & $\ldots$ & $\ldots$ \\
$\chi_{a a}(\mathrm{Cl}) / \mathrm{MHz}$ & $\ldots$ & $\ldots$ & $-32.1257(19)$ & $-36.4408(20)$ \\
$\chi_{a a}(\mathrm{Cu}) / \mathrm{MHz}$ & $\ldots$ & $\ldots$ & $16.1712(24)$ & $\ldots$ \\
$r_{0}(\mathrm{C}-\mathrm{C}) / \AA$ & $\ldots$ & $1.515321(25)$ & $\ldots$ & $\ldots$ \\
$r_{0}(\mathrm{C}-\mathrm{H}) / \AA$ & $\ldots$ & $1.077389(40)$ & $\ldots$ & $\ldots$ \\
$\angle \mathrm{HCH} / \mathrm{deg}$ & $\ldots$ & $\ldots$ & $\ldots$ & $\ldots$ \\
$r_{0}(\mathrm{M}-\mathrm{Cl}) / \AA$ & $\ldots$ & & $\ldots .05411^{\mathrm{d}}$ & $2.28356^{\mathrm{d}}$ \\
\hline \hline
\end{tabular}

\begin{tabular}{l}
\hline \hline Reference 45. \\
${ }^{\mathrm{b}}$ Reference 46. \\
${ }^{\mathrm{c}}$ Reference 47. \\
${ }^{\mathrm{d}} r_{0}(\mathrm{M}-\mathrm{Cl})$ was calculated from $B_{0}$ by using the equation $r=\left\{\mathrm{h} / 8 \pi^{2} \mu B_{0}\right\}^{1 / 2}$.
\end{tabular}


invariance to isotopic substitution at $\mathrm{M}$ and $\mathrm{Cl}$ but which are substantially smaller than the appropriate rotational constant $A_{0}$ of the $\mathrm{C}_{2 \mathrm{v}}$ isotopologue $1,1-\mathrm{d}_{2}$ cyclopropane $\left(\mathrm{CD}_{2}\right)\left(\mathrm{CH}_{2}\right)_{2}$. The decrease is larger for $\mathrm{M}=\mathrm{Cu}$ than for $\mathrm{M}=\mathrm{Ag}$. The much larger decreases in $A_{0}$, the smaller change in $B_{0}+C_{0}$, and the approximately doubled spectral intensity observed for the $\left({ }^{\mathrm{F}} \mathrm{CD}_{2}\right)\left(\mathrm{CH}_{2}\right)_{2} \cdots \mathrm{MCl}$ isotopologues compared with those of $\left({ }^{\mathrm{B}} \mathrm{CD}_{2}\right)\left(\mathrm{CH}_{2}\right)_{2} \cdots \mathrm{MCl}$ isotopologues also suggest that the orientation of the cyclopropane subunit is such that the $\mathrm{MCl}$ molecule interacts with the centre of one of the $\mathrm{C}-\mathrm{C}$ bonds, as depicted in Figure 6. Finally, the fact that $B_{0}$ and $C_{0}$ are changed very little by isotopic substitution at $\mathrm{M}$ shows that this atom lies close to the molecular centre of mass for both $\mathrm{M}=\mathrm{Cu}$ and $\mathrm{Ag}$, and therefore it is the metal atom that is contiguous with the pseudo- $\pi$ bond.

These qualitative conclusions are reinforced when the planar moments $P_{\alpha}$ of the various isotopologues of the $\left(\mathrm{CH}_{2}\right)_{3} \cdots \mathrm{MCl}$ molecules are considered. $P_{\alpha}$ is defined by the following:

$$
P_{\alpha}=\frac{1}{2}\left(-I_{\alpha}+I_{\beta}+I_{\gamma}\right)=\sum_{i} m_{i} \alpha_{i}^{2},
$$

where $\alpha, \beta$, and $\gamma$ are to be permuted cyclically over $a, b$, and $c$. The sum on the right-hand side is over the principalaxis coordinates $\alpha_{i}$ of all atoms $i$. Values of all three $P_{\alpha}$ are included in Tables I-IV for each isotopologue of both molecules $\left(\mathrm{CH}_{2}\right)_{3} \cdots \mathrm{MCl}(\mathrm{M}=\mathrm{Cu}$ or $\mathrm{Ag})$ investigated and the $P_{\alpha}$ of the free molecules $\left({ }^{12} \mathrm{CH}_{2}\right)_{3}$ and $\left(\mathrm{CD}_{2}\right)\left(\mathrm{CH}_{2}\right)_{2}$ are given in Table V. Comparison of the cyclopropane and the $\left(\mathrm{CH}_{2}\right)_{3} \cdots \mathrm{MCl}$ values allows the immediate conclusion that only the $\mathrm{H}$ (or D) atoms lie outside the $a b$ principal plane in both $\left(\mathrm{CH}_{2}\right)_{3} \cdots \mathrm{CuCl}$ and $\left(\mathrm{CH}_{2}\right)_{3} \cdots \mathrm{AgCl}$. This is clear from (a) the close correspondence of $P_{c}=\sum_{i} m_{i} c_{i}^{2}$ for each $\left({ }^{12} \mathrm{CH}_{2}\right)_{3} \cdots \mathrm{MCl}$ isotopologue with $P_{c}=\sum_{i} m_{i} c_{i}^{2}$ of $\left({ }^{12} \mathrm{CH}_{2}\right)_{3}$ (note that the three $\mathrm{C}$ atoms of cyclopropane lie in the $a b$ plane) and (b) their independence of the $\mathrm{M}$ or $\mathrm{Cl}$ isotope involved. The small differences can be attributed to a combination of minor changes in the geometry of the $\mathrm{CH}_{2}$ groups on formation of the complex and zero-point motion differences between free cyclopropane and the complex. The fact that the more weakly bound $\left(\mathrm{CH}_{2}\right)_{3} \cdots \mathrm{AgCl}$ exhibits a larger change from cyclopropane than does $\left(\mathrm{CH}_{2}\right)_{3} \cdots \mathrm{CuCl}$ suggests that zero-point effects contribute more than geometry changes. When values for $\left({ }^{\mathrm{B}} \mathrm{CD}_{2}\right)\left(\mathrm{CH}_{2}\right)_{2} \cdots \mathrm{MCl}$ and $\left({ }^{\mathrm{F}} \mathrm{CD}_{2}\right)\left(\mathrm{CH}_{2}\right)_{2} \cdots \mathrm{MCl}$ are examined, we find a similar conclusion, namely, that $P_{c}=\sum_{i} m_{i} c_{i}^{2}$ for the complex is nearly the same as the corresponding quantity (also $P_{c}$ ) of 1,1- $\mathrm{d}_{2}$ cyclopropane and is again independent of $\mathrm{M}$ or $\mathrm{Cl}$ isotope. Note also that for the $\mathrm{CD}_{2}$ isotopologues, $P_{c}$ is independent of the position of the substitution (front or back) and is almost identical for both $\mathrm{M}=\mathrm{Cu}$ and $\mathrm{Ag}$ within experimental error.

A comparison of $P_{b}=\sum_{i} m_{i} b_{i}^{2}$ for the complexes with $P_{b}$ for either $\left({ }^{12} \mathrm{CH}_{2}\right)_{3}$ or $1,1-\mathrm{d}_{2}$ cyclopropane, as appropriate, shows that this quantity in the complex is always greater than that of the free cyclopropane molecule, with the values being about $2.8 \mathrm{u} \AA^{2}$ larger for the complex when $\mathrm{M}=\mathrm{Cu}$ but about $2.0 \mathrm{u} \AA^{2}$ larger when $\mathrm{M}=\mathrm{Ag}$, independently of whether isotopic substitution is at $\mathrm{M}, \mathrm{Cl}$ or ${ }^{\mathrm{B}} \mathrm{C}$. This provides strong evidence that the front ${ }^{\mathrm{F}} \mathrm{C}-{ }^{\mathrm{F}} \mathrm{C}$ bond lengthens on complex formation, the more so for $\mathrm{M}=\mathrm{Cu}$ than for $\mathrm{Ag}$. For ${ }^{\mathrm{F}} \mathrm{CD}_{2}$ isotopologues, the changes from $P_{b}$ of 1,1- $\mathrm{d}_{2}$ cyclopropane are 6.20 and $5.3 \mathrm{u} \AA^{2}$ for $\mathrm{M}=\mathrm{Cu}$ and $\mathrm{Ag}$, respectively, again suggesting that the ${ }^{\mathrm{F}} \mathrm{C}-{ }^{\mathrm{F}} \mathrm{C}$ bond expansion is greater for $\mathrm{M}$ $=\mathrm{Cu}$.

Finally, when zero-point moments of inertia are employed, the pseudo-inertia defect resulting from only the atoms that are coplanar, (i.e., from the $\mathrm{C}, \mathrm{M}$, and $\mathrm{Cl}$ atoms), after the contribution of the six $\mathrm{H}$ atoms have been removed, is given by

$$
\Delta_{0} \approx 2\left(P_{c}^{\text {cyclopropane }}-P_{c}^{\text {complex }}\right) .
$$

Eq. (3) is valid in the approximation that the contribution $6 m_{\mathrm{H}} c_{\mathrm{H}}^{2}$ of the $\mathrm{H}$ atoms to the appropriate planar moments of the complex and free cyclopropane is identical.

For the isotopologue $\left({ }^{12} \mathrm{CH}_{2}\right)_{3} \cdots{ }^{107} \mathrm{Ag}^{35} \mathrm{Cl}, \quad \Delta_{0}$ $=-0.320(1) \mathrm{u} \AA^{2}$, while for $\left({ }^{12} \mathrm{CH}_{2}\right)_{3} \cdot{ }^{63} \mathrm{Cu}^{35} \mathrm{Cl}$, the result is $-0.150(13) \mathrm{u} \AA^{2}$. For planar molecules, $\Delta_{0}$ is usually small and positive. Small negative values do occur for planar molecules when large-amplitude, out-of-plane, low frequency vibrational modes contribute predominantly to the zero-point motion, however. The pseudo-inertia defects $\Delta_{0}$ calculated for $\left({ }^{12} \mathrm{CH}_{2}\right)_{3} \cdots \cdot \mathrm{H}^{35} \mathrm{Cl}$ and $\left({ }^{12} \mathrm{CH}_{2}\right)_{3} \cdot{ }^{35} \mathrm{ClF}$ from data in Refs. 29 and 30 are $0.25(4)$ and $0.17(2) \mathrm{u}^{2}$, respectively. Inertia defects $\Delta_{0}$ of the corresponding (planar) complexes in which ethyne is the Lewis base are somewhat larger and positive and become smaller as the intermolecular binding becomes stronger. For example, the values are 1.2(3), 0.639(2), 0.34(4), and $0.285(4) \mathrm{u} \AA^{2}$ for the T-shaped complexes of $\mathrm{C}_{2} \mathrm{H}_{2}$ with $\mathrm{H}^{35} \mathrm{Cl},{ }^{35} \mathrm{ClF},{ }^{107} \mathrm{Ag}^{35} \mathrm{Cl}$ and ${ }^{63} \mathrm{Cu}^{35} \mathrm{Cl}$, respectively. ${ }^{24,25,12,13}$ Increasingly positive inertia defects are usually attributed to a predominant contribution of a low-lying, large-amplitude, in-plane vibration to the zero-point motion and this effect will presumably become more important as the intermolecular binding strength decreases. The order of binding strength in the $\mathrm{C}_{2} \mathrm{H}_{2}$ complexes is $\mathrm{HCl}<\mathrm{ClF}<\mathrm{AgCl}<\mathrm{CuCl}$. The different patterns of behaviour of the pseudo-inertia defect in the corresponding series when cyclopropane is the Lewis base are probably attributable to (1) small changes in the out-of-plane hydrogen coordinates $c_{\mathrm{H}}$ in the strongly bound species $\left({ }^{12} \mathrm{CH}_{2}\right)_{3} \ldots{ }^{63} \mathrm{Cu}{ }^{35} \mathrm{Cl}$ and $\left({ }^{12} \mathrm{CH}_{2}\right)_{3} \cdot{ }^{107} \mathrm{Ag}^{35} \mathrm{Cl}$ coupled with (2) a decreasing importance of the contribution of the low-lying, in-plane vibration to the zero-point motion in the order $\mathrm{HCl}>\mathrm{ClF}>\mathrm{AgCl}>\mathrm{CuCl}$.

\section{Quantitative geometry}

The discussion in Section III B 1 suggests that the qualitative geometry of $\left(\mathrm{CH}_{2}\right)_{3} \cdots \mathrm{MCl}(\mathrm{M}=\mathrm{Cu}$ or $\mathrm{Ag})$ is of the type shown in Figure 6 and has $\mathrm{C}_{2 \mathrm{v}}$ symmetry. Thus, all atoms but $\mathrm{H}$ lie in the $a b$ principal inertia plane, which is a plane of symmetry, and the atoms are in the indicated order. The mid-point of the ${ }^{\mathrm{F}} \mathrm{C}-{ }^{\mathrm{F}} \mathrm{C}$ bond (denoted by ${ }^{*}$ ) and the $\mathrm{M}$ and $\mathrm{Cl}$ nuclei all lie on the $a$-axis. Insufficient isotopic substitution was available in the cyclopropane subunit to allow a determination of an $r_{\mathrm{s}}$ geometry of cyclopropane when it is within either complex, and hence a $r_{0}$ geometry is more appropriate here. Isotopic substitution at $\mathrm{M}$ and $\mathrm{Cl}$ is available in both complexes, however, so that $r_{\mathrm{s}}$ coordinates of these atoms can be determined, as Costain ${ }^{48}$ suggested, by using zero-point moments of inertia 
TABLE VI. Comparison of $r_{\mathrm{s}}, r_{0}$, and $r_{\mathrm{e}}$ principal-axis coordinates and bond lengths determined for $\left(\mathrm{CH}_{2}\right)_{3} \cdots \mathrm{MCl}(\mathrm{M}=\mathrm{Cu} \text { or } \mathrm{Ag})^{\mathrm{a}}$

\begin{tabular}{|c|c|c|c|c|c|c|}
\hline \multirow[b]{3}{*}{ Coordinate/bond length } & \multicolumn{6}{|c|}{ Parent isotopologue } \\
\hline & \multicolumn{3}{|c|}{$\left({ }^{12} \mathrm{CH}_{2}\right)_{3} \cdots{ }^{63} \mathrm{Cu}^{35} \mathrm{Cl}$} & \multicolumn{3}{|c|}{$\left({ }^{12} \mathrm{CH}_{2}\right)_{3} \cdots{ }^{107} \mathrm{Ag}^{35} \mathrm{Cl}$} \\
\hline & $r_{\mathrm{s}}$ & $r_{0}(\text { fit } 1)^{\mathrm{a}}$ & Ab initio $r_{\mathrm{e}}^{\mathrm{b}}$ & $r_{\mathrm{s}}$ & $r_{0}(\text { fit } 1)^{\mathrm{a}}$ & Ab initio $r_{\mathrm{e}}^{\mathrm{b}}$ \\
\hline$a_{\mathrm{M}} / \AA$ & $0.196(76)$ & $0.2076(22)$ & 0.1919 & $0.191(79)$ & $0.1891(18)$ & 0.1850 \\
\hline$a_{\mathrm{Cl}} / \AA$ & $2.2779(66)$ & $2.2688(20)$ & 2.2540 & $2.4658(60)$ & $2.4764(30)$ & 2.4612 \\
\hline$r(\mathrm{M} \cdots \mathrm{Cl}) / \AA$ & $2.082(77)$ & $2.0612(42)$ & 2.0621 & $2.275(79)$ & $2.2872(48)$ & 2.2763 \\
\hline
\end{tabular}

${ }^{a}$ Fit 1 is that in which the $r(\mathrm{C}-\mathrm{H})$ are released but the angular orientation of the $\mathrm{CH}_{2}$ groups is fixed at the ab initio values (see text and Table VII).

${ }^{\mathrm{b}}$ A $b$ initio calculation conducted at the $\operatorname{CCSD}(\mathrm{T})\left(\mathrm{F} 12^{*}\right) /$ aug-cc-pVTZ-F12 level of theory.

in the appropriate equilibrium expression due to the work of Kraitchman, ${ }^{49}$ as reproduced in the following:

$$
\left|a_{\mathrm{M} \text { or Cl}}\right|=\left\{\left(\Delta I_{b}+\Delta I_{c}\right) / 2 \mu_{\mathrm{S}}\right\}^{\frac{1}{2}},
$$

where $\mu_{\mathrm{S}}=\Delta m M /(\Delta m+M)$ and $\Delta I_{b}$ and $\Delta I_{c}$ are the changes in the principal moments of inertia that accompany a mass change $\Delta m$ on substitution into a parent isotopologue of mass $M$. The values of $a_{\mathrm{M}}$ and $a_{\mathrm{Cl}}$ determined for each of $\left({ }^{12} \mathrm{CH}_{2}\right)_{3} \ldots{ }^{63} \mathrm{Cu}{ }^{35} \mathrm{Cl}$ and $\left({ }^{12} \mathrm{CH}_{2}\right)_{3} \cdot{ }^{107} \mathrm{Ag}^{35} \mathrm{Cl}$ as parent molecules are given in Table VI, which also includes the substitution distances $r_{\mathrm{s}}(\mathrm{Cu} \cdots \mathrm{Cl})$ and $r_{\mathrm{s}}(\mathrm{Ag} \cdots \mathrm{Cl})$ that thereby become available. The signs of $a_{\mathrm{M}}$ were chosen so that these distances were in agreement with the $r_{0}$ values to be discussed later. The coordinates of the atoms $\mathrm{M}$ are small, but it has been shown elsewhere $e^{9,12,13}$ that substitution coordinates of heavy atoms, such as $\mathrm{Cu}$ or $\mathrm{Ag}$, near the centre of mass do not suffer the serious underestimation that occurs for lighter atoms in the same situation. Nevertheless, the recommendation by Costain $^{48}$ that errors in $r_{\mathrm{s}}$ coordinates should be estimated as $\delta a=0.015 \AA / a$ has been followed for both $a_{\mathrm{M}}$ and $a_{\mathrm{Cl}}$.

Initial attempts to determine the complete $r_{0}$ geometry of each molecule $\left(\mathrm{CH}_{2}\right)_{3} \cdots \mathrm{MCl}(\mathrm{M}=\mathrm{Cu}$ or $\mathrm{Ag})$ failed because of high correlation and ill-conditioning, which led to large errors in bond lengths and angles. To avoid this problem, quantities well-determined in the $a b$ initio calculation at the $\operatorname{CCSD}(\mathrm{T})$ $\left(\mathrm{F} 12^{*}\right)$ /aug-cc-pVTZ-F12 level, but of minor chemical interest here, were assumed unchanged. Two such approaches were tested; in both, $\mathrm{C}_{2 \mathrm{v}}$ symmetry was assumed, with all heavy atoms coplanar, as concluded in Section III B 1. In the first, the angles defining the orientation of the two equivalent ${ }^{\mathrm{F}} \mathrm{CH}_{2}$ groups and the angles $\mathrm{H}^{\mathrm{F}} \mathrm{CH}$ and $\mathrm{H}^{\mathrm{B}} \mathrm{CH}$ were so fixed (fit 1 ). The results obtained by using Kisiel's program STRFIT ${ }^{50}$ to fit the three principal moments of inertia of all isotopologues investigated are shown in Table VII. In a second approach (fit 2), the distances $r\left({ }^{\mathrm{F}} \mathrm{C}-\mathrm{H}\right)$ and $r\left({ }^{\mathrm{B}} \mathrm{C}-\mathrm{H}\right)$ were fixed at their $a b$ initio values while the angle $\mathrm{H}-{ }^{\mathrm{F}} \mathrm{C}-\mathrm{H}$ and the angle made by the bisector of the $\mathrm{H}-{ }^{\mathrm{F}} \mathrm{C}-\mathrm{H}$ group with the ${ }^{\mathrm{F}} \mathrm{C}-{ }^{\mathrm{F}} \mathrm{C}$ internuclear line were fitted. The geometry determined in this way is also given in Table VII. A comparison of the two approaches shows satisfactory agreement between the two, especially among the quantities of most chemical interest, namely, the distances $r_{0}\left({ }^{\mathrm{F}} \mathrm{C}-{ }^{\mathrm{F}} \mathrm{C}\right), r_{0}\left({ }^{\mathrm{B}} \mathrm{C}-{ }^{\mathrm{F}} \mathrm{C}\right), r_{0}\left({ }^{*} \cdots \mathrm{M}\right)$ (where ${ }^{*}$ denotes the centre of the $\mathrm{C}-\mathrm{C}$ bond) and $r_{0}(\mathrm{M}-\mathrm{Cl})$, the last of which is in both cases in excellent agreement with the $r_{\mathrm{s}}$ version available in Table VI. The two main features of note are the increase in $r_{0}\left({ }^{\mathrm{F}} \mathrm{C}-{ }^{\mathrm{F}} \mathrm{C}\right)$ and the decrease in $r_{0}\left({ }^{\mathrm{B}} \mathrm{C}-{ }^{\mathrm{F}} \mathrm{C}\right)$ relative to the $\mathrm{C}-\mathrm{C}$ distance in free cyclopropane (see Table $\mathrm{V}$ ) for both $\mathrm{M}=\mathrm{Cu}$ and $\mathrm{Ag}$. Evidently, the interaction of the atom $\mathrm{M}$ of $\mathrm{MCl}$ with the front $\mathrm{C}-\mathrm{C}$ bond of cyclopropane on forming molecules $\left(\mathrm{CH}_{2}\right)_{3} \cdots \mathrm{MCl}(\mathrm{M}=\mathrm{Cu}$ or $\mathrm{Ag})$ is strong enough to perturb significantly the pseudo- $\pi$ bond. It will be demonstrated in Section IV that the bond extension considerably

TABLE VII. $r_{0}$ and ab initio $r_{\mathrm{e}}$ geometries determined for $\left(\mathrm{CH}_{2}\right)_{3} \cdots \mathrm{MCl}(\mathrm{M}=\mathrm{Cu}$ or $\mathrm{Ag}){ }^{\mathrm{a}}$

\begin{tabular}{lcccccc}
\hline \hline & \multicolumn{3}{c}{$\left(\mathrm{CH}_{2}\right)_{3} \cdots \mathrm{CuCl}$} & \multicolumn{3}{c}{$\left(\mathrm{CH}_{2}\right)_{3} \cdots \mathrm{AgCl}$} \\
\cline { 2 - 7 } Geometric quantity & $r_{0}(\text { fit } 1)^{\mathrm{b}}$ & $r_{0}(\text { fit } 2)^{\mathrm{c}}$ & $r_{\mathrm{e}}(\text { ab initio })^{\mathrm{d}}$ & $r_{0}(\text { fit 1 })^{\mathrm{b}}$ & $r_{0}(\text { fit } 2)^{\mathrm{c}}$ & $r_{\mathrm{e}}(\text { ab initio })^{\mathrm{d}}$ \\
\hline$r(\mathrm{M}-\mathrm{Cl}) / \AA$ & $2.0612(42)$ & $2.0594(43)$ & 2.0621 & $2.2872(48)$ & $2.2793(36)$ & 2.2763 \\
$r\left(\mathrm{M}-{ }^{*}\right) / \AA^{\mathrm{e}}$ & $1.9912(46)$ & $1.9930(50)$ & 1.9555 & $2.3069(54)$ & $2.3078(46)$ & 2.3047 \\
$r\left({ }^{\mathrm{F}} \mathrm{C}-{ }^{\mathrm{F}} \mathrm{C}\right) / \AA$ & $1.6177(9)$ & $1.6214(20)$ & 1.6088 & $1.5880(17)$ & $1.5966(29)$ & 1.5750 \\
$r\left({ }^{\mathrm{F}} \mathrm{C}-{ }^{\mathrm{B}} \mathrm{C}\right) / \AA$ & $1.469(4)$ & $1.470(5)$ & 1.4955 & $1.486(8)$ & $1.501(9)$ & 1.4968 \\
$r\left({ }^{\mathrm{F}} \mathrm{C}-\mathrm{H}\right) / \AA$ & $1.0825(29)$ & {$[1.0836]$} & 1.0836 & $1.0861(61)$ & {$[1.0820]$} & 1.0820 \\
$r\left({ }^{\mathrm{B}} \mathrm{C}-\mathrm{H}\right) / \AA$ & $1.0883(53)$ & {$[1.0797]$} & 1.0797 & $1.092(10)$ & {$[1.0797]$} & 1.0797 \\
$\angle \mathrm{H}-{ }^{\mathrm{F}} \mathrm{C}-{ }^{*} / \mathrm{deg}$ & {$[118.94]$} & $118.5(3)$ & 118.94 & {$[118.67]$} & $117.7(4)$ & 118.67 \\
$\angle \mathrm{H}-{ }^{\mathrm{B}} \mathrm{C}-{ }^{*} / \mathrm{deg}$ & {$[122.34]$} & $122.6(4)$ & 122.34 & {$[122.21]$} & $121.7(6)$ & 122.21 \\
$\angle \mathrm{H}-{ }^{\mathrm{F}} \mathrm{C}-{ }^{*}-{ }^{\mathrm{B}} \mathrm{C} / \mathrm{deg}$ & {$[104.49]$} & {$[104.49]$} & 104.49 & {$[105.20]$} & {$[105.20]$} & 105.20 \\
\hline \hline
\end{tabular}

\footnotetext{
${ }^{\mathrm{a}}$ See text for nomenclature used to label the front and back $\mathrm{C}$ atoms.

${ }^{\mathrm{b}} \mathrm{Geometry}$ fitted to moments of inertia by assuming the angles enclosed in square brackets from the $a b$ initio calculation.

${ }^{\mathrm{c}}$ Geometry fitted to moments of inertia by assuming the $r(\mathrm{C}-\mathrm{H})$ and the dihedral angle enclosed in square brackets from the $a b$ initio calculation.

${ }^{\mathrm{d}}$ Optimised geometry calculated $a b$ initio at the $\operatorname{CCSD}(\mathrm{T})\left(\mathrm{F} 12^{*}\right) /$ aug-cc-pVTZ-F12 level of theory. See text for details.

$\mathrm{e}_{*}$ denotes the midpoint of the bond ${ }^{\mathrm{F}} \mathrm{C}-{ }^{\mathrm{F}} \mathrm{C}$.
} 
TABLE VIII. A comparison of a range of properties determined for the complexes $\mathrm{B} \cdots \mathrm{MCl}$, where $\mathrm{B}$ is $\mathrm{C}_{2} \mathrm{H}_{2}, \mathrm{C}_{2} \mathrm{H}_{4}$ or $\left(\mathrm{CH}_{2}\right)_{3}$ and $\mathrm{M}$ is $\mathrm{Cu}$ or $\mathrm{Ag}$.

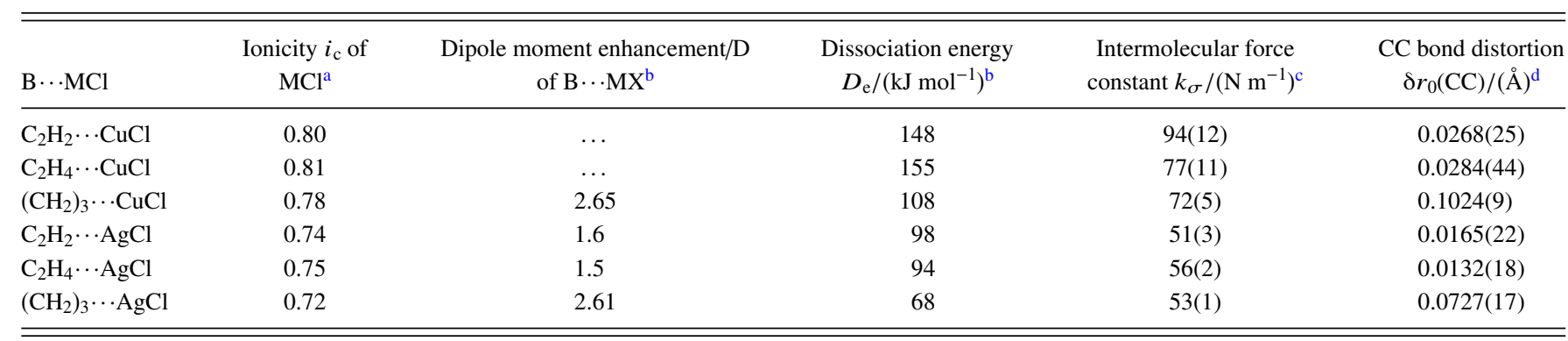

${ }^{\mathrm{a}}$ As calculated from $\chi_{a a}(\mathrm{Cl})$ with the aid of Eq. (5).

${ }^{\mathrm{b}}$ From $a b$ initio calculations reported in Refs. $12-14$ and this work.

${ }^{\mathrm{c}}$ From Refs. $12-14$ and this work. Calculated from centrifugal distortion constants $\Delta_{J}$ by means of Eq. (6).

${ }^{\mathrm{d}} \delta r_{0}(\mathrm{CC})=r_{0}(\mathrm{CC})_{\text {complex }}-r_{0}(\mathrm{CC})_{\text {free } \mathrm{B}}$, the increase in $r_{0}$ length of the $\mathrm{C}-\mathrm{C} \pi$ - or pseudo- $\pi$ bond of $\mathrm{B}$ in forming a complex B $\cdots \mathrm{MX}$.

exceeds those in the corresponding molecules ethyne $\cdots \mathrm{MCl}$ and ethene $\cdots \mathrm{MCl}$. A reason for this will be presented.

\section{Other experimental and ab initio calculated properties of $\left(\mathrm{CH}_{2}\right)_{3} \cdots \mathrm{MCl}$}

There are several properties, in addition to the detailed geometry discussed in Section III B, that are available from experimental and ab initio results reported here for $\left(\mathrm{CH}_{2}\right)_{3} \cdots \mathrm{MCl}(\mathrm{M}=\mathrm{Cu}$ or $\mathrm{Ag})$. These include information about the strength of the interaction of $\left(\mathrm{CH}_{2}\right)_{3}$ and $\mathrm{MCl}$, and the electric charge rearrangement on formation of $\left(\mathrm{CH}_{2}\right)_{3} \cdots \mathrm{MCl}$.

The $\mathrm{M}$ and $\mathrm{Cl}$ nuclear quadrupole coupling constants carry information about how the components of the e.f.g. tensor $V_{\alpha \beta}^{\mathrm{X}}$ ( $\alpha$ and $\beta$ to be permuted over $a, b$, and $c, \mathrm{X}=\mathrm{Cu}$ or $\mathrm{Cl}$ ) at these nuclei change when $\left(\mathrm{CH}_{2}\right)_{3} \cdots \mathrm{MCl}$ is formed from $\mathrm{MCl}$. The coupling constants are defined as $\chi_{\alpha \beta}(\mathrm{X})=-(e Q / h) V_{\alpha \beta}^{\mathrm{X}}$. Values of $\chi_{a a}(\mathrm{Cu})$ and $\chi_{a a}(\mathrm{Cl})$ observed for the isotopologues $\left({ }^{12} \mathrm{CH}_{2}\right)_{3} \cdot{ }^{63} \mathrm{Cu}^{35} \mathrm{Cl}$ and $\left({ }^{12} \mathrm{CH}_{2}\right)_{3} \cdot{ }^{107} \mathrm{Ag}^{35} \mathrm{Cl}$ are in Tables I and III, respectively. The corresponding experimental quantities ${ }^{47}$ for the free molecules ${ }^{63} \mathrm{Cu}^{35} \mathrm{Cl}$ and ${ }^{107} \mathrm{Ag}^{35} \mathrm{Cl}$ are collected in Table V. Clearly, in forming $\left(\mathrm{CH}_{2}\right)_{3} \cdots \mathrm{MCl}$ from $\mathrm{MCl}$, the magnitude of the e.f.g. at $\mathrm{Cl}$ along the $a$ axis direction (which coincides with the $\mathrm{MCl}$ internuclear axis) significantly decreases, both when $\mathrm{M}=\mathrm{Cu}$ or $\mathrm{Ag}$. Similarly, the $a a$ component of the e.f.g. at $\mathrm{Cu}$ changes. (No equivalent comment about the e.f.g. at $\mathrm{Ag}$ is possible because the nuclear electric quadrupole moment for $\mathrm{Ag}$ is zero.)

The fractional ionic characters (or ionicities), $i_{\mathrm{c}}$, of the free molecules ${ }^{63} \mathrm{Cu}^{35} \mathrm{Cl}$ and ${ }^{107} \mathrm{Ag}^{35} \mathrm{Cl}$ are available from their $\chi_{a a}(\mathrm{Cl})$ values recorded in Table V. The Townes-Dailey model $^{51,52}$ for interpreting nuclear quadrupole coupling constants leads to the expression

$$
i_{c}=1+\left\{\chi_{a a}(\mathrm{Cl}) / e Q q_{3,1,0}(\mathrm{Cl})\right\}
$$

in which $e Q q_{3,1,0}(\mathrm{Cl})(=109.74 \mathrm{MHz})^{52}$ is the contribution to the coupling constant from a single $3 \mathrm{p}_{z}$ electron of Cl. The results are $i_{\mathrm{c}}=0.70$ and 0.67 for ${ }^{63} \mathrm{Cu}^{35} \mathrm{Cl}$ and ${ }^{107} \mathrm{Ag}^{35} \mathrm{Cl}$, respectively. If the valence bond description of $\mathrm{MCl}$ is employed, these results imply contributions of $70 \%$ and $67 \%$ from the ionic form $\mathrm{M}^{+} \mathrm{Cl}^{-}$when $\mathrm{M}=\mathrm{Cu}$ and $\mathrm{Ag}$, respectively. For the complexes $\left({ }^{12} \mathrm{CH}_{2}\right)_{3} \cdots{ }^{63} \mathrm{Cu}^{35} \mathrm{Cl}$ and $\left({ }^{12} \mathrm{CH}_{2}\right)_{3} \cdots{ }^{107} \mathrm{Ag}^{35} \mathrm{Cl}$, the corresponding approach leads to $i_{\mathrm{c}}=0.78$ and 0.72 , respectively. The ionic character $i_{\mathrm{c}}$ has been similarly established for a number of complexes $\mathrm{B} \cdots \mathrm{MCl}$ in which $\mathrm{B}$ is a simple Lewis base and $\mathrm{M}$ is either $\mathrm{Cu}$ or $\mathrm{Ag}$, and are tabulated elsewhere,,${ }^{14}$ including those cases in which $\mathrm{B}$ is a $\pi$-electron donor. Table VIII compares the values of $i_{\mathrm{c}}$ for $\mathrm{C}_{2} \mathrm{H}_{2} \cdots \mathrm{MCl}, \mathrm{C}_{2} \mathrm{H}_{4} \cdots \mathrm{MCl}$, and $\left(\mathrm{CH}_{2}\right)_{3} \cdots \mathrm{MCl}$ for $\mathrm{M}=\mathrm{Cu}$ and $\mathrm{Ag}$. We conclude that when $\mathrm{MCl}$ approaches the $\pi$-bond of either ethyne or ethene or the pseudo- $\pi$ bond of cyclopropane, the existing partial positive charge on the $\mathrm{M}$ atom is stabilised by partial delocalisation onto the hydrocarbon and allows thereby an increase in the ionic character of $\mathrm{MCl}$. The ionic character appears to be smaller in the case of the cyclopropane complexes, however. Unfortunately, the Townes-Dailey model cannot be applied in its simple form to the coupling constants $\chi_{a a}\left({ }^{63} \mathrm{Cu}\right)$ of ${ }^{63} \mathrm{Cu}^{35} \mathrm{Cl}$ and $\left({ }^{12} \mathrm{CH}_{2}\right)_{3} \cdot{ }^{63} \mathrm{Cu}^{35} \mathrm{Cl}$ in order to assess more directly the change in positive charge at $\mathrm{Cu}$ and the internal consistency of this approach. This is because the valence shell electrons are s electrons and predict, in the Townes-Dailey approximation, $\chi_{a a}(\mathrm{Cu})=0$.

The electric dipole moments have been calculated $a b$ initio at the level and by the method described in Section II. The results are 6.09 and $8.06 \mathrm{D}$ for $\left(\mathrm{CH}_{2}\right)_{3} \cdots \mathrm{CuCl}$ and $\left(\mathrm{CH}_{2}\right)_{3} \cdots \mathrm{AgCl}$, respectively, corresponding to enhancements of 2.65 and $2.61 \mathrm{D}$ over the values for $\mathrm{CuCl}$ and $\mathrm{AgCl}$ calculated at the same level of theory. These enhancements confirm the conclusion drawn from the $\mathrm{Cl}$ nuclear quadrupole coupling constants that there is significant electric charge redistribution when the complexes $\left(\mathrm{CH}_{2}\right)_{3} \cdots \mathrm{MCl}(\mathrm{M}=\mathrm{Cu}$ or $\mathrm{Ag}$ ) are formed from cyclopropane and $\mathrm{MCl}$.

The fact of significant electric charge movement when each $\left(\mathrm{CH}_{2}\right)_{3} \cdots \mathrm{MCl}$ is formed and the accompanying significant distortions of the cyclopropane ring identified in Section III B indicate that these complexes are strongly bound. This is confirmed by the equilibrium dissociation energy for the process $\left(\mathrm{CH}_{2}\right)_{3} \cdots \mathrm{MCl} \rightarrow\left(\mathrm{CH}_{2}\right)_{3}+\mathrm{MCl}$ which has been calculated at the $\operatorname{CCSD}(\mathrm{T})\left(\mathrm{F} 12^{*}\right) /$ aug-cc-pVTZF12 level of theory for both $\mathrm{M}=\mathrm{Cu}$ and $\mathrm{M}=\mathrm{Ag}$. The values after correction for basis set superposition error are $D_{\mathrm{e}}=108$ and $68 \mathrm{~kJ} \mathrm{~mol}^{-1}$ for $\mathrm{M}=\mathrm{Cu}$ and $\mathrm{Ag}$, respectively. Table VIII includes $D_{\mathrm{e}}$ obtained from $a b$ initio calculations conducted at similar levels of theory for the $\pi$-type complexes ethyne $\cdots \mathrm{MCl}^{12,13}$ and ethene $\cdots \mathrm{MCl}^{9,13}$ as well as those reported here for cyclopropane $\cdots \mathrm{MCl}$. Comparison of the $D_{\mathrm{e}}$ in Table VIII shows that the complex $\mathrm{B} \cdots \mathrm{CuCl}$ is significantly more strongly bound than the complex $\mathrm{B} \cdots \mathrm{AgCl}$ for a given $\mathrm{B}$, whether B = ethyne, ethene, or cyclopropane, while, for a given $\mathrm{M}$, the cyclopropane complex is more weakly bound 
than those involving ethyne or ethene, according to the $D_{\mathrm{e}}$ criterion.

Another criterion of binding strength is the intermolecular stretching force constant $k_{\sigma}$ which is the restoring force per unit infinitesimal displacement from equilibrium of the intermolecular bond along the molecular symmetry axis. For molecules such as $\left(\mathrm{CH}_{2}\right)_{3} \cdots \mathrm{MCl}(\mathrm{M}=\mathrm{Cu}$ or $\mathrm{Ag})$, in which $\mathrm{MCl}$ lies along the molecular symmetry axis $C_{2}^{a}$, Millen ${ }^{53}$ has shown that $k_{\sigma}$ may be calculated from the centrifugal distortion constant $\Delta_{J}$ in the quadratic approximation by means of the expression

$$
k_{\sigma}=\left(\frac{8 \pi^{2} \mu}{\Delta_{J}}\right)\left[B^{3}(1-b)+C^{3}(1-c)\right] .
$$

In Eq. (6), $\mu=\left(m_{\text {cyclo }} m_{\mathrm{MCl}}\right) /\left(m_{\text {cyclo }}+m_{\mathrm{MCl}}\right)$ and $b=\left(B / B_{\text {cyclo }}\right.$ $\left.+B / B_{\mathrm{MCl}}\right)$ and there is a corresponding expression for $c$. The spectroscopic constants of the complex, free cyclopropane, and $\mathrm{MCl}$ should be equilibrium values but in their absence, zero-point values, which are available from Tables I-V, are employed. The component molecules are assumed rigid in deriving Eq. (6). For the most abundant isotopologues $\left({ }^{12} \mathrm{CH}_{2}\right)_{3} \cdot{ }^{63} \mathrm{Cu}^{35} \mathrm{Cl}$ and $\left({ }^{12} \mathrm{CH}_{2}\right)_{3} \ldots{ }^{107} \mathrm{Ag}^{35} \mathrm{Cl}$, the calculated values are $k_{\sigma}=72(5)$ and $53(1) \mathrm{N} \mathrm{m}^{-1}$, respectively, where the error quoted is that propagated from the error in $\Delta_{J}$. Systematic errors arising from assumptions in deriving Eq. (6) will be significant here. For example, it is assumed that the geometry of both cyclopropane and MX are unchanged on formation of the complex and that the component molecules are rigid. It has been shown that the cyclopropane and $\mathrm{MCl}$ geometries do change when within $\left(\mathrm{CH}_{2}\right)_{3} \cdots \mathrm{MCl}$. Moreover, $\mathrm{CuCl}$ and $\mathrm{AgCl}$ have force constants that are not very large (i.e., these diatomic molecules are not rigid). Hence, the values of $k_{\sigma}$ presented should be treated cautiously. Table VIII includes $k_{\sigma}$ values for the series $\mathrm{B} \cdots \mathrm{MCl}$ for $\mathrm{B}=$ ethyne, ${ }^{12,13}$ ethene, ${ }^{9,13}$ and cyclopropane and $\mathrm{M}=\mathrm{Cu}$ or $\mathrm{Ag}$. Bearing in mind the caveat about its accuracy, the $k_{\sigma}$ criterion suggests that the order of interaction strength is $\mathrm{Cu}>\mathrm{Ag}$ for a given $\mathrm{B}$, as also indicated by $D_{\mathrm{e}}$. The order ethyne $\approx$ ethene $>$ cyclopropane for a given $\mathrm{M}$ suggested by $D_{\mathrm{e}}$ values is reproduced by the $k_{\sigma}$ for $\mathrm{M}=\mathrm{Cu}$, but is less clear for $\mathrm{M}=\mathrm{Ag}$, however.

Another property of the $\pi$ and pseudo- $\pi$ complexes that could be affected by the strength of the $\mathrm{B} \cdots \mathrm{MCl}$ interaction is the change $\delta r_{0}(\mathrm{CC})=r_{0}(\mathrm{CC})_{\text {complex }}-r_{0}(\mathrm{CC})_{\text {free B }}$ in the $\pi$ or pseudo- $\pi \mathrm{CC} r_{0}$ bond length from that of free $\mathrm{B}$ (ethyne, ethene, or cyclopropane) when subsumed into the complex. These quantities ${ }^{9,12,13}$ are included in Table VIII for B $\cdots \mathrm{MX}$ for all three $\mathrm{B}$ and for $\mathrm{M}=\mathrm{Cu}$ or $\mathrm{Ag}$. We note that the more strongly bound $\mathrm{Cu}$ complexes show larger distortions than the corresponding Ag complexes. The cyclopropane $\cdots \mathrm{MCl}$ complexes, which are evidently more weakly bound than their ethyne or ethene counterparts for a given $\mathrm{M}$, show a significantly greater lengthening $\delta r_{0}$ (CC) than do the ethyne or ethene complexes. Reasons for this will be advanced in Section IV.

\section{CONCLUSIONS}

Complexes $\left(\mathrm{CH}_{2}\right)_{3} \cdots \mathrm{MCl}(\mathrm{M}=\mathrm{Cu}$ or $\mathrm{Ag})$, formed through the non-covalent interaction of cyclopropane with each of cuprous chloride or argentous chloride, have been generated in the gas phase by the laser ablation of either copper or silver in the presence of supersonically expanded pulses of a gas mixture containing small amounts of cyclopropane and carbon tetrachloride in a large excess of argon. The rotational spectra of the complexes so formed were detected with a chirped-pulse, Fourier-transform microwave spectrometer and analysed to give rotational constants and $\mathrm{Cu}$ and $\mathrm{Cl}$ nuclear quadrupole coupling constants for eight isotopologues of each of $\left(\mathrm{CH}_{2}\right)_{3} \cdots \mathrm{CuCl}$ and $\left(\mathrm{CH}_{2}\right)_{3} \cdots \mathrm{AgCl}$. The geometry of each of these complexes was established unambiguously to be of the type shown in Figure 6, each having $C_{2 v}$ symmetry, with all $\mathrm{C}$ atoms coplanar, and with the $\mathrm{MCl}$ molecule lying along a median of the cyclopropane $\mathrm{C}_{3}$ triangle. This median coincides with the principal inertia axis $a$ in each of the two complexes $\left(\mathrm{CH}_{2}\right)_{3} \cdots \mathrm{MCl}$. The $\mathrm{M}$ atom interacts with the pseudo- $\pi$ bond linking the pair of equivalent carbon atoms ${ }^{\mathrm{F}} \mathrm{C}$ nearest to it, so that $\mathrm{M}$ forms a non-covalent bond to one $\mathrm{C}-\mathrm{C}$ edge of the cyclopropane molecule. The $\left(\mathrm{CH}_{2}\right)_{3} \cdots \mathrm{MCl}$ complexes have angular geometries (see Figure 6) which are isomorphous with those of their hydrogen- and halogen-bonded analogues $\left(\mathrm{CH}_{2}\right)_{3} \cdots \mathrm{HCl}$ and $\left(\mathrm{CH}_{2}\right)_{3} \cdots \mathrm{ClF}$, respectively, shown (drawn to scale) in Figure 3. Quantitative details of the geometries were determined by interpretation of the observed rotational constants of 8 isotopologues for each complex $\left(\mathrm{CH}_{2}\right)_{3} \cdots \mathrm{CuCl}$ and $\left(\mathrm{CH}_{2}\right)_{3} \cdots \mathrm{AgCl}$. The results are in good agreement with those from $a b$ initio calculations carried out at the $\operatorname{CCSD}(\mathrm{T})\left(\mathrm{F} 12^{*}\right) /$ aug-cc-pVTZ-F12 level of theory. The most interesting geometrical feature is an elongation of the ${ }^{\mathrm{F}} \mathrm{C}-{ }^{\mathrm{F}} \mathrm{C}$ bond and a shrinkage of the two ${ }^{\mathrm{B}} \mathrm{C}-{ }^{\mathrm{F}} \mathrm{C}$ bonds relative to the $\mathrm{C}-\mathrm{C}$ bond in cyclopropane itself.

A comparison of various properties of $\left(\mathrm{CH}_{2}\right)_{3} \cdots \mathrm{MCl}$ $(\mathrm{M}=\mathrm{Cu}$ or $\mathrm{Ag})$, determined either by interpretation of spectroscopic constants or by ab initio calculation, with those of the ethyne and ethene analogues $\mathrm{C}_{2} \mathrm{H}_{2} \cdots \mathrm{MCl}$ and $\mathrm{C}_{2} \mathrm{H}_{4} \cdots \mathrm{MCl}$ similarly determined (see Table VIII) suggests the following general conclusions. For a given $\pi$ or pseudo- $\pi$ electron donor $\mathrm{B}$, the order of the strength of the interaction is $\mathrm{CuCl}$ $>\mathrm{AgCl}$ (whether measured by the experimental intermolecular stretching force constant $k_{\sigma}$ or by the $a b$ initio calculated dissociation energy $D_{\mathrm{e}}$ ). Similarly, the increase in the ionicity $i_{\mathrm{c}}$ relative to that of free $\mathrm{CuCl}$ or $\mathrm{AgCl}$ (as calculated from the $\mathrm{Cl}$ nuclear quadrupole coupling constant) and the electric dipole moment enhancement also support this conclusion (see Table VIII). For a given $\mathrm{MCl}$, the data collected in Table VIII suggest (but not as convincingly) that the order of binding strength is ethyne $\approx$ ethene $>$ cyclopropane. An apparent exception is the increase in the $r_{0}(\mathrm{CC})$ bond length $\delta r_{0}(\mathrm{CC})=r_{0}(\mathrm{CC})_{\text {complex }}-r_{0}(\mathrm{CC})_{\text {free } \mathrm{B}}$ when $\mathrm{B} \cdots \mathrm{MCl}$ is formed. We note that the more weakly bound species $\left(\mathrm{CH}_{2}\right)_{3} \cdots \mathrm{MCl}$ have values of $\delta r_{0}(\mathrm{CC})$ that are ca. 4 times larger than those of their $\mathrm{C}_{2} \mathrm{H}_{2} \cdots \mathrm{MCl}$ and $\mathrm{C}_{2} \mathrm{H}_{4} \cdots \mathrm{MCl}$ analogues, despite the fact that the last two are more strongly bound than the first. A possible explanation for this striking observation lies in the nature of the pseudo- $\pi$ bond in cyclopropane, which is shown schematically in Figure 2. When $\mathrm{MCl}$ interacts with the pseudo- $\pi$ bond, electron density is presumably transferred to $\mathrm{MCl}$, thereby weakening the $\mathrm{CC}$ single bond. If ethene is the electron donor, removal of a similar amount of $\pi$-electron density to $\mathrm{MCl}$ would weaken the $\mathrm{CC}$ 
bond less (and therefore not lengthen it as much) because there is still a single bond present, in addition to the weakened $\pi$ bond. A similar argument applies to the $\mathrm{C} \equiv \mathrm{C}$ bond in ethyne.

The investigations of the complexes $\mathrm{H}_{2} \cdots \mathrm{CuF}$, $\mathrm{H}_{2} \cdots \mathrm{CuCl}, \mathrm{H}_{2} \cdots \mathrm{AgCl}$, and $\mathrm{H}_{2} \cdots \mathrm{AuCl}$ by Novick and co-workers ${ }^{16-19}$ lead to similar but with somewhat larger distortions, namely, that the $\mathrm{H}-\mathrm{H}$ bond increases in length by ca. $0.087 \AA, 0.058 \AA, 0.055 \AA$, and $\sim 0.12 \AA$, respectively, i.e., by ca. $11.5 \%, 7.7 \%, 7.3 \%$, and $\sim 16 \%$, respectively, when $\mathrm{H}_{2}$ becomes bound to MX. The percentage increases in length for the ${ }^{\mathrm{F}} \mathrm{C}-{ }^{\mathrm{F}} \mathrm{C}$ bond in $\left(\mathrm{CH}_{2}\right)_{3} \cdots \mathrm{CuCl}$ and $\left(\mathrm{CH}_{2}\right)_{3} \cdots \mathrm{AgCl}$ are $6.8 \%$ and $4.8 \%$, respectively. The lengthening of the $\mathrm{H}-\mathrm{H}$ bond in $\mathrm{H}_{2} \cdots \mathrm{CuF}$ and $\mathrm{H}_{2} \cdots \mathrm{AgCl}$ might also be explained in a similar way to that proposed here for cyclopropane complexes, but the effects of changes in the zero-point motion will presumably make a more important contribution when hydrogen, rather than cyclopropane, is the Lewis base.

\section{ACKNOWLEDGMENTS}

The authors thank the EPSRC and the School of Chemistry at Newcastle University for the award of a DTA postgraduate studentship to D.M.B., the European Research Council for a postdoctoral fellowship awarded to D.P.Z., a postgraduate studentship to J.C.M., and for project funding (Grant No. CPFTMW-307000). D.P.Z. also thanks Newcastle University for a SAgE Research Fellowship. A.C.L. thanks the University of Bristol for a Senior Research Fellowship and Newcastle University for a Visiting Professor award. D.P.T. is pleased to acknowledge The Royal Society for the award of a University Research Fellowship. We are also grateful to the EPSRC UK National Service for Computational Chemistry Software (NSCCS) at Imperial College London.

${ }^{1}$ R. S. Walters, P. v. R. Schleyer, C. Corminboeuf, and M. A. Duncan, J. Am. Chem. Soc. 127, 1100 (2005).

${ }^{2}$ D. M. P. Mingos, J. Organomet. Chem. 635, 1-8 (2001).

${ }^{3}$ S. G. Francis, S. L. Matthews, O. K. Poleshchuk, N. R. Walker, and A. C. Legon, Angew. Chem., Int. Ed. 45, 6341-6343 (2006).

${ }^{4}$ S. J. Harris, A. C. Legon, N. R. Walker, and D. E. Wheatley, Angew. Chem., Int. Ed. 49, 181-183 (2010).

${ }^{5}$ V. A. Mikhailov, D. P. Tew, N. R. Walker, and A. C. Legon, Chem. Phys. Lett. 499, 16-20 (2010).

${ }^{6}$ V. A. Mikhailov, F. J. Roberts, S. L. Stephens, S. J. Harris, D. P. Tew, J. N. Harvey, N. R. Walker, and A. C. Legon, J. Chem. Phys. 134, 134305 (2011). ${ }^{7}$ S. L. Stephens, D. P. Tew, N. R. Walker, and A. C. Legon, J. Mol. Spectrosc. 267, 163-168 (2011).

${ }^{8}$ N. R. Walker, D. P. Tew, S. J. Harris, D. E. Wheatley, and A. C. Legon, J. Chem. Phys. 134, 014307 (2011).

${ }^{9}$ S. L. Stephens, D. P. Tew, V. A. Mikhailov, N. R. Walker, and A. C. Legon, J. Chem. Phys. 135, 024315 (2011).

${ }^{10}$ S. L. Stephens, W. Mizukami, D. P. Tew, N. R. Walker, and A. C. Legon, J. Chem. Phys. 136, 064306 (2012).

${ }^{11}$ S. Z. Riaz, S. L. Stephens, W. Mizukami, D. P. Tew, N. R. Walker, and A. C. Legon, Chem. Phys. Lett. 531, 1-5 (2012).

${ }^{12}$ S. L. Stephens, W. Mizukami, D. P. Tew, N. R. Walker, and A. C. Legon, J. Chem. Phys. 137, 174302 (2012).

${ }^{13}$ S. L. Stephens, D. M. Bittner, V. A. Mikhailov, W. Mizukami, D. P. Tew, N. R. Walker, and A. C. Legon, Inorg. Chem. 53, 10722-10730 (2014).

${ }^{14}$ D. M. Bittner, D. P. Zaleski, S. L. Stephens, D. P. Tew, N. R. Walker, and A. C. Legon, J. Chem. Phys. 142, 144302 (2015).
${ }^{15}$ D. P. Zaleski, S. L. Stephens, D. P. Tew, D. M. Bittner, J. C. Mullaney, N. R. Walker, and A. C. Legon, Phys. Chem. Chem. Phys. 17, 19230 (2015).

${ }^{16}$ D. J. Frohman, G. S. Grubbs II, Z. Yu, and S. E. Novick, Inorg. Chem. 52, 816-822 (2013).

${ }^{17}$ H. M. Pickett, D. A. Obenchain, G. S. Grubbs, and S. E. Novick, in 68th International Symposium on Molecular Spectroscopy [TH16] (The Ohio State University, Columbus, OH, 2013).

${ }^{18}$ G. S. Grubbs II, D. A. Obenchain, H. M. Pickett, and S. E. Novick, J. Chem. Phys. 141, 114306 (2014).

${ }^{19}$ D. A. Obenchain, G. S. Grubbs II, H. M. Pickett, and S. E. Novick, in 68 th International Symposium on Molecular Spectroscopy [FC03] (The Ohio State University, Columbus, OH, 2013).

${ }^{20}$ A. C. Legon and D. J. Millen, Faraday Discuss. Chem. Soc. 73, 71-87 (1982).

${ }^{21}$ A. C. Legon and D. J. Millen, Chem. Soc. Rev. 16, 467-498 (1987).

${ }^{22}$ A. C. Legon, Chem. - Eur. J. 4, 1890-1897 (1998).

${ }^{23}$ A. C. Legon, Angew. Chem., Int. Ed. 38, 2686-2714 (1999).

${ }^{24}$ A. C. Legon, P. D. Aldrich, and W. H. Flygare, J. Chem. Phys. 75, 625-630 (1981).

${ }^{25}$ K. Hinds, J. H. Holloway, and A. C. Legon, J. Chem. Soc., Faraday Trans. 92, 1291-1296 (1996).

${ }^{26}$ P. D. Aldrich, A. C. Legon, and W. H. Flygare, J. Chem. Phys. 75, 2126-2134 (1981).

${ }^{27}$ H. I. Bloemink, J. H. Holloway, and A. C. Legon, Chem. Phys. Lett. 250, 567-575 (1996).

${ }^{28}$ C. A. Coulson and W. E. Moffitt, Philos. Mag. 40, 1 (1949).

${ }^{29}$ A. C. Legon, P. D. Aldrich, and W. H. Flygare, J. Am. Chem. Soc. 104, 1486-1490 (1982).

${ }^{30}$ K. Hinds, J. H. Holloway, and A. C. Legon, J. Chem. Soc., Faraday Trans. 93, 373-378 (1997).

${ }^{31}$ S. L. Stephens and N. R. Walker, J. Mol. Spectrosc. 263, 27-33 (2010).

${ }^{32}$ D. P. Zaleski, S. L. Stephens, and N. R. Walker, Phys. Chem. Chem. Phys. 16, 25221-25228 (2014).

${ }^{33}$ PGOPHER, a program for simulating rotational structure, version 6.0.202, designed by C. M. Western, University of Bristol, 2010. Available at http:// pgopher.chm.bris.ac.uk.

${ }^{34}$ K. Raghavachari, G. W. Trucks, J. A. Pople, and M. Head-Gordon, Chem. Phys. Lett. 157, 479-483 (1989).

${ }^{35}$ C. Hättig, D. P. Tew, and A. Köhn, J. Chem. Phys. 132, 231102 (2010).

${ }^{36}$ R. A. Kendall, T. H. Dunning, Jr., and R. J. Harrison, J. Chem. Phys. 96, 6796 (1992)

${ }^{37}$ T. H. Dunning, Jr., K. A. Peterson, and A. K. Wilson, J. Chem. Phys. 114, 9244 (2001).

${ }^{38}$ K. A. Peterson and C. Puzzarini, Theor. Chem. Acc. 114, 283 (2005).

${ }^{39}$ D. Figgen, G. Rauhut, M. Dolg, and H. Stoll, Chem. Phys. 311, 227-244 (2005).

${ }^{40}$ O. Christiansen, H. Koch, and P. Jørgensen, Chem. Phys. Lett. 243, 409-418 (1995).

${ }^{41}$ H.-J. Werner, P. J. Knowles, R. Lindh, F. R. Manby, M. Schütz et al., Molpro, version 2009.1, a package of ab initio programs, 2009, see http://www. molpro.net.

${ }^{42}$ C. Hättig and F. Weigend, J. Chem. Phys. 113, 5154 (2000).

${ }^{43}$ J. K. G. Watson, J. Chem. Phys. 48, 4517 (1968).

${ }^{44}$ See supplementary material at http://dx.doi.org/10.1063/1.4934539 for fits of spectroscopic constants to observed transition frequencies for each isotopologue investigated.

${ }^{45}$ T. Brubacher, C. Styger, B. Vogelsanger, I. Ozier, and A. Bauder, J. Mol. Spectrosc. 138, 197-203 (1989).

${ }^{46}$ Y. Endo, M. C. Chang, and E. Hirota, J. Mol. Spectrosc. 126, 63-71 (1987).

${ }^{47}$ K. D. Hensel, C. Styger, W. Jäger, A. J. Merer, and M. C. L. Gerry, J. Phys. Chem. 99, 3320-3328 (1993).

${ }^{48}$ C. C. Costain, J. Chem. Phys. 29, 864 (1958).

${ }^{49}$ J. Kraitchman, Am. J. Phys. 21, 17-24 (1953).

${ }^{50}$ Z. Kisiel, J. Mol. Spectrosc. 218, 58-67 (2003).

${ }^{51}$ C. H. Townes and B. P. Dailey, J. Chem. Phys. 23, 118-123 (1955).

${ }^{52}$ W. Gordy and R. L. Cook, in Microwave Molecular Spectra, Technique of Organic Chemistry Vol. 9, edited by A. Wiessberger (Interscience, New York, 1970), Chap. 14.

${ }^{53}$ D. J. Millen, Can. J. Chem. 63, 1477-1479 (1985). 